\title{
Argentina 2017: LA DINÁMICA INTERTEMPORAL DE LA REESTRUCTURACIÓN ECONÓMICA*
}

\author{
Argentina 2017: The Intertemporal \\ Dynamics of Economic Reform
}

\section{CARLOS FREYTES}

Universidad Torcuato Di Tella, Argentina

\section{SARA NIEDZWIECKI}

University of California, Santa Cruz, Estados Unidos

\begin{abstract}
RESUMEN
El principal hecho político en Argentina durante 2017 fue el triunfo del gobierno de Cambiemos en las elecciones de medio término. Ese resultado fue favorecido por la estrategia del gobierno de administrar la dinámica intertemporal del ajuste económico. Antes de las elecciones, el gobierno difirió medidas y llevó adelante una política económica que, más allá de empoderar a los ganadores (principalmente al sector agropecuario), compensó a los perdedores (trabajadores, adultos mayores y el sector informal) mediante la recomposición de sus ingresos. La contrapartida de esta estrategia fue un significativo aumento del stock de deuda y el deterioro de las cuentas fiscales y externas. Después de las elecciones, los adultos mayores, el sector informal y las clases medias sufrieron una mayor imposición de costos. Este informe analiza las políticas del gobierno antes y después de las elecciones, prestando particular atención a su estrategia de prorrogar los costos del ajuste y de negociación con ganadores y perdedores. Hacia adelante, el gobierno enfrenta la difícil tarea de reconciliar la resolución de los desequilibrios económicos acumulados sin erosionar los apoyos sociales que le permitieron imponerse en las elecciones legislativas.
\end{abstract}

Palabras clave: Argentina, Cambiemos, Macri, elecciones 2017, políticas públicas

\begin{abstract}
The Cambiemos victory in the midterm elections was the most important political event in Argentina during 2017. The government achieved this result by managing the intertemporal dynamics of economic adjustment. Before the elections, the government deferred unpopular measures and pursued an economic policy that, beyond empowering the winners (mainly the agricultural sector), compensated the losers (workers, seniors, and the informal sector) by increasing their income. The counterpart of this strategy was a significant increase in the external debt stocks and the deterioration of fiscal and external accounts. After
\end{abstract}

Los autores agradecen a Juan Germano, socio de Isonomía Consultores, y a Javier Zelaznik y Carlos Gervasoni, por el acceso a los datos de Isobarómetro y del Índice de Confianza en el Gobierno de la Universidad Torcuato Di Tella, respectivamente. Agradecemos también a Juan Manuel Menéndez por su excelente asistencia para este trabajo. 
the elections, the elderly, the informal sector, and the middle class suffered a greater imposition of costs. This report analyzes Argentina's government policies before and after the elections, paying particular attention to its strategy of deferring the costs of adjustment and its negotiation with winners and losers. Going forward, the government faces the difficult task of solving accumulated economic imbalances without eroding the social support that allowed it to prevail in the legislative elections.

Keywords: Argentina, Cambiemos, Macri, 2017 elections, public policy

\section{INTRODUCCIÓN}

El gobierno encabezado por Mauricio Macri ganó las elecciones presidenciales de 2015 derrotando al Frente para la Victoria (FPV), que había gobernado la Argentina durante 12 años. Su llegada a la Casa Rosada implicó una serie de novedades: es la primera vez en la historia democrática del país que gobierna un presidente que no pertenece a una de las dos fuerzas mayoritarias que dominaron la vida política argentina durante el siglo XX, el peronismo (Partido Justicialista, PJ) y el radicalismo (Unión Cívica Radical, UCR). Es también la primera vez que un gobierno de centroderecha que no oculta sus preferencias programáticas llega al gobierno por la vía democrática. Crucial para la llegada de Mauricio Macri a la presidencia fue la decisión de un grupo de dirigentes de la centenaria UCR y otros partidos filorradicales, en especial la Coalición Cívica (CC), de atar su destino electoral al de Propuesta Republicana (PRO), el partido con el que Macri conquistó la jefatura de gobierno de la Ciudad de Buenos Aires desde 2007.

La alianza Cambiemos, resultado de esa decisión, consagró una suerte de división del trabajo entre los socios de la coalición: por un lado, las redes provinciales de la UCR le aportaron al PRO el alcance territorial del que carecía, sobre todo en el interior del país. Por otro lado, la UCR y en especial la CC sumaron a la propuesta de racionalización económica encarnada por el PRO cierta capacidad para interpelar a los sectores medios con una promesa de regeneración institucional y transparencia en el ejercicio del gobierno. El PRO, en tanto, además de la orientación programática general, aportó a la coalición comprobada capacidad de gobierno en la gestión de la Ciudad de Buenos Aires y, lo más decisivo, un candidato presidencial competitivo con el que capitalizar el malhumor social de los últimos años del kirchnerismo. La división del trabajo inicial se mantuvo en el ejercicio del gobierno: mientras que el PRO mantuvo un celoso control de la gestión gubernamental y una férrea centralización de las decisiones dentro del gabinete, los demás socios de la coalición cumplieron un rol más importante en el Congreso y en el vínculo con la opinión pública.

Esa división del trabajo político y de gobierno subtiende el funcionamiento de Cambiemos como una coalición de centroderecha. Esta caracterización alude a la orientación programática general del gobierno, y es consistente con las preferencias de políticas públicas de sus cuadros económicos y técnicos, la 
afinidad del partido con los diagnósticos y las propuestas de la comunidad de negocios y la distribución de las preferencias electorales de los sectores mediosaltos (Freytes 2015a). En efecto, distintos segmentos del empresariado operaron en los hechos como la core constituency del PRO a través, por ejemplo, de la contribución decisiva de los aportes privados de campaña (Freiller 2015). La percepción de una amenaza generalizada a los intereses de las elites empresarias durante el gobierno del FPV jugó también un rol central en la movilización política de esas elites, y en su disposición a sostener el trabajo político del nuevo partido y a involucrarse personalmente en la actividad pública (Vommaro 2017a). Por último, tanto en las mediciones de opinión como en la inferencia ecológica, el voto por Cambiemos crece entre los sectores de clase media y alta, las personas con estudios terciarios o universitarios, y los que habitan en distritos o barrios con mayor poder adquisitivo (Natanson 2017, Isonomía Consultores 2018).

Cambiemos llegó al gobierno de la mano de una promesa general de cambio, contra el trasfondo de un descontento mayoritario e intenso en los sectores medios y medios-altos, por el rendimiento decreciente de la experiencia kirchnerista en el terreno económico (Murillo et al. 2016). El programa económico de Cambiemos vino a anclar esa promesa imprecisa de cambio y se constituyó en el núcleo innegociable de su gestión. Durante el primer año, bajo el signo de la normalización de la economía, ese programa implicó liberalizar el mercado cambiario, resolver las demandas de los acreedores externos y reestablecer el acceso a los mercados internacionales de crédito (Vommaro y Gené 2017). En el mediano plazo, el objetivo de Cambiemos es producir una reorientación general de la política económica implementada por el FPV, caracterizada por un modelo de economía semicerrada, basado en el consumo interno, con cierta voluntad industrializadora y el Estado ocupando un rol central como regulador y árbitro de los conflictos distributivos. La propuesta es virar a un modelo de economía más abierta e integrada a los flujos de comercio internacional, con un Estado en retirada, la inversión antes que el consumo privado como motor de crecimiento y una estrategia de inserción internacional basada en sectores intensivos en recursos naturales y la exportación de servicios con alto valor agregado. ${ }^{1}$

La reconversión de la economía argentina hacia un modelo más abierto constituye así un objetivo central del gobierno de Cambiemos. La ambición y el carácter refundacional de esa agenda económica contrastaba sin embargo con las condiciones de su llegada al gobierno, en una situación minoritaria en el Congreso, con apoyos territoriales desiguales (Freytes y Niedzwiecki 2016) y teniendo enfrente a una sociedad civil activada por la experiencia previa de gobierno (Vommaro y Gené 2017). Ambos factores plantearon desde los inicios un interrogante sobre la viabilidad política de esta experiencia. El cual se encontraba mediado en el imaginario colectivo por la última experiencia

Ver por ejemplo “Bases firmes para la economía argentina”, Carta de Jefatura de Gabinete $N^{\circ} 1$, accesible en: https://www.casarosada.gob.ar/images/CartaJefatura/CartaJG_01.pdf. 
de un gobierno no peronista, que había concluido con la salida anticipada del gobierno de la Alianza UCR-Frepaso y la peor crisis social y política desde el regreso a la democracia.

En este contexto, en 2017 el gobierno debía enfrentar las elecciones de medio término luego de un año recesivo, sin logros apreciables en materia económica y con niveles de inflación todavía altos. Cambiemos gozaba todavía de crédito social, pero los indicadores de aprobación de la gestión y de sus principales figuras se habían ido deteriorando al compás de los magros resultados económicos. La otra incógnita que planteaba el año electoral era qué ocurriría con el polo peronista. Ese polo se encontraba en una situación de fragmentación partidaria y legislativa y con serias dificultades para resolver las disputas internas desatadas desde la salida del gobierno del FPV.

En una mirada retrospectiva, y a juzgar por los acontecimientos de 2017, lo novedoso de Cambiemos en el gobierno es la prudencia política -resumida por el término gradualismo- con la que se propuso llevar adelante sus objetivos económicos. Esto es: el gobierno priorizó en todo momento la sustentabilidad del viraje propuesto, incluso si eso exigía postergar medidas centrales de su programa económico, como la reducción del déficit fiscal o la reforma laboral.

Esa estrategia fue políticamente eficaz: Cambiemos se impuso en las elecciones legislativas, obteniendo más del $40 \%$ de los votos a nivel nacional, y triunfando en 13 de las 24 provincias argentinas. Estos resultados le permitieron sumar 21 diputados y 9 senadores a la coalición. La contracara de este éxito político fue, de un modo quizás paradójico dado la orientación programática del gobierno, el deterioro de las cuentas públicas y del sector externo, incluyendo el crecimiento del déficit comercial y el aumento del stock de deuda. Luego de las elecciones, la administración se abocó a enfrentar esos desequilibrios, lo que implicó en la práctica la imposición de nuevos costos a los perdedores del modelo, un aumento de la conflictividad social y un deterioro apreciable de sus niveles de aprobación social.

Este informe analiza el año político de la Argentina desde el punto de vista de las políticas de Cambiemos antes y después de las elecciones, prestando particular atención a la administración intertemporal de los costos del ajuste y al manejo de su relación con los ganadores y perdedores de la reestructuración económica. El resto del artículo se organiza de la siguiente manera: en la sección 2 abordamos las estrategias de política macroeconómica y de empoderamiento del sector agropecuario, mientras se compensa a los perdedores a través de la política social. La sección 3 describe la coyuntura política, atendiendo a los fundamentos simbólicos de la reproducción de los apoyos sociales al gobierno, en particular los temas de la corrupción y la demanda de orden. Nos ocupamos luego de la fragmentación del peronismo, dedicándole especial atención a las cruciales elecciones en la provincia de Buenos Aires para ilustrar los dilemas de ese polo opositor. La sección 4 describe los resultados electorales y el impacto de las elecciones en la composición del Congreso. En la sección 5 nos ocupamos 
del período posterior a las elecciones, describiendo el ajuste poselectoral en el área impositiva y previsional, la intensificación de la protesta y el deterioro de los índices de popularidad del gobierno. La sección 6 concluye haciendo un balance sobre el estado de la democracia en Argentina.

\section{CONTEXTO SOCIOECONÓMICO}

\section{La lógica política de la política macroeconómica}

Cambiemos enfrentaba un test decisivo en las elecciones de medio término. 2016 había sido un año recesivo. El gobierno disfrutó durante su primer año en la Casa Rosada de un crédito social vinculado con la expectativa de cambio que llevó a Mauricio Macri al poder. La existencia de ese crédito social era apreciable en las mediciones de opinión pública. Las encuestas mostraban una brecha persistente entre, por un lado, la evaluación positiva de la gestión y la expectativa de una mejora futura de la situación del país, en torno al $50 \%$ y $60 \%$ de las opiniones. Y, por otro lado, la percepción de mejora de la situación personal respecto de un año atrás, que se ubicaba apenas en torno al $10 \%$ (Gráfico 1). La falta de una mejoría a nivel personal no hacía mella en la aprobación general porque era atribuida a los problemas heredados de la gestión anterior (Isonomía Consultores 2018). El índice de confianza en el gobierno elaborado por la Universidad Torcuato Di Tella arrojaba un resultado similar: mientras que los indicadores genéricos de honestidad y capacidad del gobierno se mantuvieron a lo largo de 2016 en valores altos, los vinculados con el desempeño efectivo de la administración (evaluación general, eficiencia en la gestión y orientación hacia el interés general) se ubicaron consistentemente un punto por debajo (Gráfico 2). En suma, había una expectativa de mejora y cierta confianza en el rumbo general del gobierno, pese a la falta de resultados tangibles en el plano personal.

No obstante, en los primeros meses de 2017 la falta de resultados en materia económica comenzaba a perjudicar su imagen. En efecto, la combinación de devaluación, recorte a los subsidios de los servicios básicos (que motivaron aumentos de las tarifas de electricidad, gas y agua), inflación persistente y pérdida de poder adquisitivo de los salarios tuvo durante el 2016 un impacto apreciable sobre la capacidad de consumo de los hogares, generando descontento entre las clases medias y bajas (Natanson 2017). Para febrero y marzo de 2017, si bien el gobierno mantenía todavía altos índices de aprobación, la expectativa de mejora de la situación del país y de los hogares, al igual que la confianza en la efectividad de la gestión, habían sufrido un lento pero persistente deterioro y se encontraban en su punto más bajo desde diciembre de 2015 (Gráficos 1 y 2). 
Gráfico 1. Evaluación del gobierno, situación general del país y situación económica personal

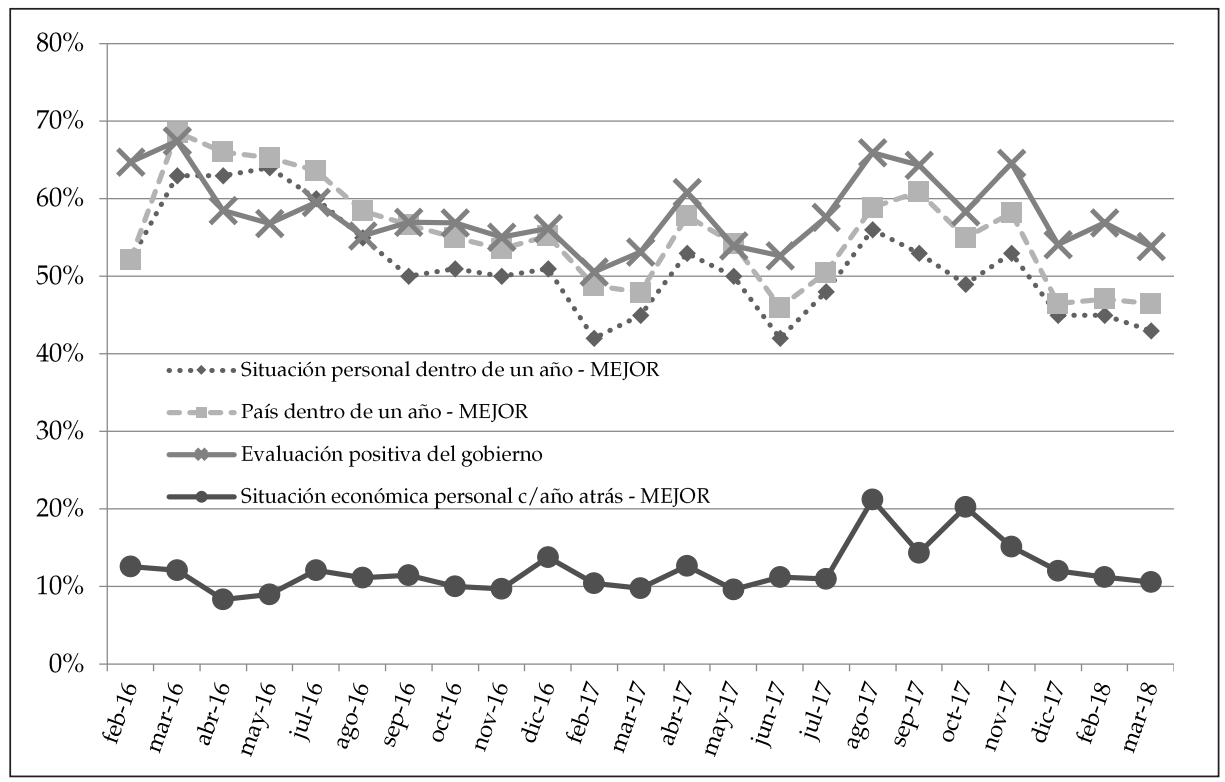

Fuente: elaboración propia en base a datos de Isonomía Consultores (2018).

Gráfico 2. Índice de confianza en el gobierno.

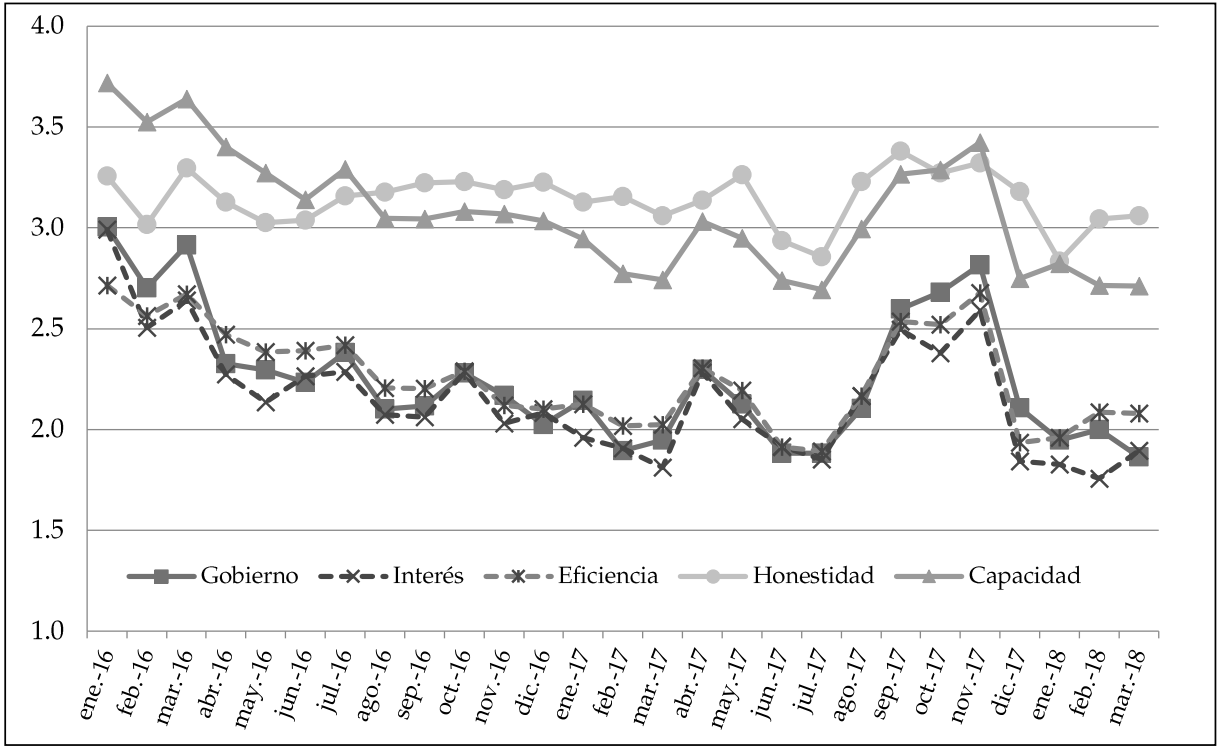

Fuente: elaboración propia en base al Índice de Confianza en el Gobierno, Universidad Torcuato Di Tella. 
Para comienzos del segundo trimestre del año, la percepción de un descontento pronunciado con la marcha de la economía marcaba el comportamiento de los actores políticos: no obstante las compensaciones recibidas por las organizaciones sindicales durante 2016, en marzo la Confederación General del Trabajo (CGT) estimó imprudente seguir ignorando el malestar de las bases y convocó al primer paro nacional contra la política económica de Cambiemos. En tanto la oposición, en particular aquellos sectores que se referenciaban en la expresidenta Cristina Fernández de Kirchner, apostaba a hacer del deterioro de la situación económica el eje de la campaña electoral, con la expectativa de capitalizar el descontento social en los comicios de octubre.

La política económica del gobierno antes de las elecciones iba a frustrar esa aspiración. En efecto, durante la primera parte del año el gobierno implementó una serie de medidas orientadas a recomponer los ingresos de los sectores medios, los asalariados y el sector informal. Los ajustes de las tarifas de servicios públicos, de menor magnitud que los de 2016, se concentraron en el primer trimestre del año y fueron postergados luego hasta después de las elecciones. El mantenimiento de las transferencias sociales, incluyendo los mecanismos de aumento automático sancionados durante el gobierno anterior y la expansión de la cobertura, benefició al sector informal; mientras que una leve apreciación del tipo de cambio en el segundo y tercer trimestre del año, que contribuyó a anclar los precios y desacelerar la inflación, recompuso los ingresos de los sectores medios (Banco Central de la República Argentina 2018a). Por último, la expansión de la obra pública y el crédito hipotecario hizo que la construcción fuera uno de los motores de crecimiento económico durante 2017 (Indec 2018a).

La recuperación de la economía desde el segundo trimestre del año permitió mantener estables los niveles agregados de empleo, pese a que se verificó una disminución del empleo industrial, una caída del empleo privado formal y un aumento de modalidades más precarias de empleo (Ministerio de Trabajo 2018; CetyD 2018). A partir de inicios del 2017 se observó una recomposición de los salarios reales del sector formal en relación a la inflación, y esta brecha positiva aumentó a partir de los acuerdos paritarios celebrados en el segundo trimestre. Aunque insuficientes para recuperar lo perdido durante el 2016, ambos desarrollos favorecieron una cierta recuperación del salario real (ver Gráfico 4). La combinación de crecimiento económico y mantenimiento de los programas sociales tuvo además un impacto favorable sobre las mediciones de pobreza (Indec 2018b). 
Gráfico 3. Evolución mensual de la actividad económica (EMAE), imagen de Mauricio Macri y aprobación del gobierno

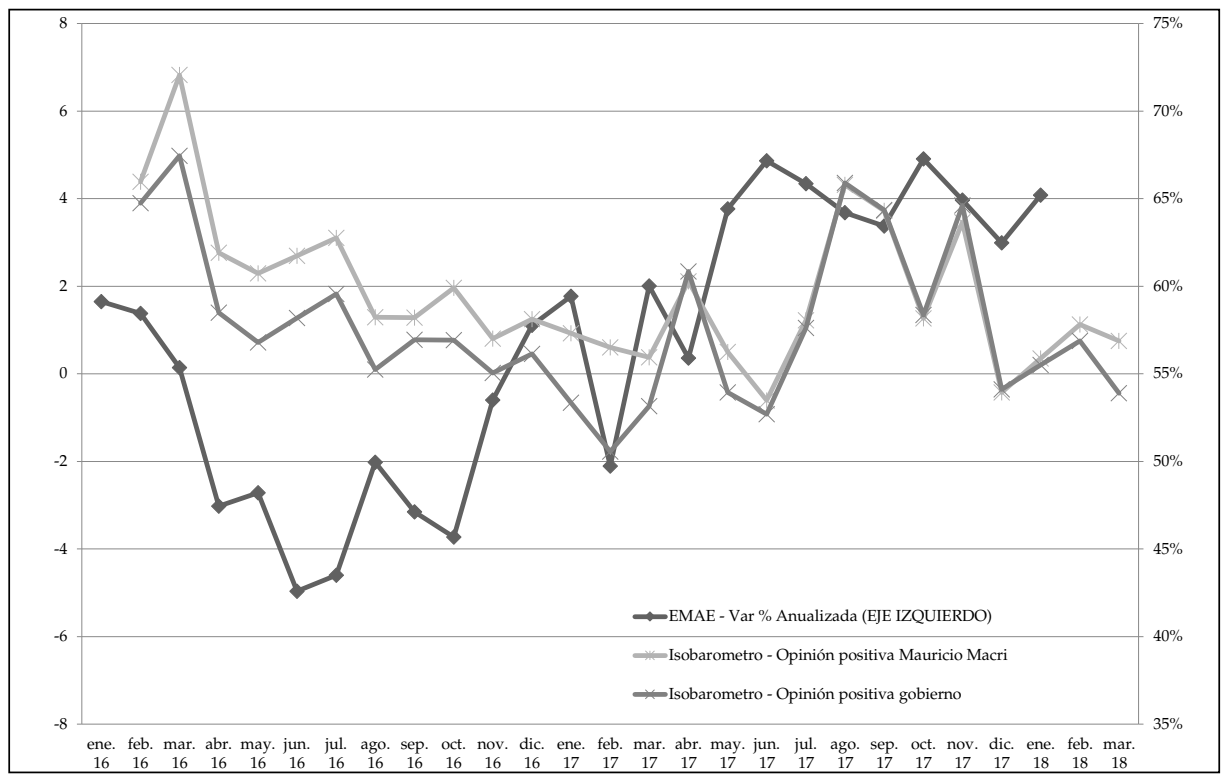

Fuente: elaboración propia en base a datos de Indec e Isonomía Consultores (2018).

Gráfico 4. Inflación mensual anualizada, evolución de salarios del sector formal, imagen de Mauricio Macri y aprobación del gobierno

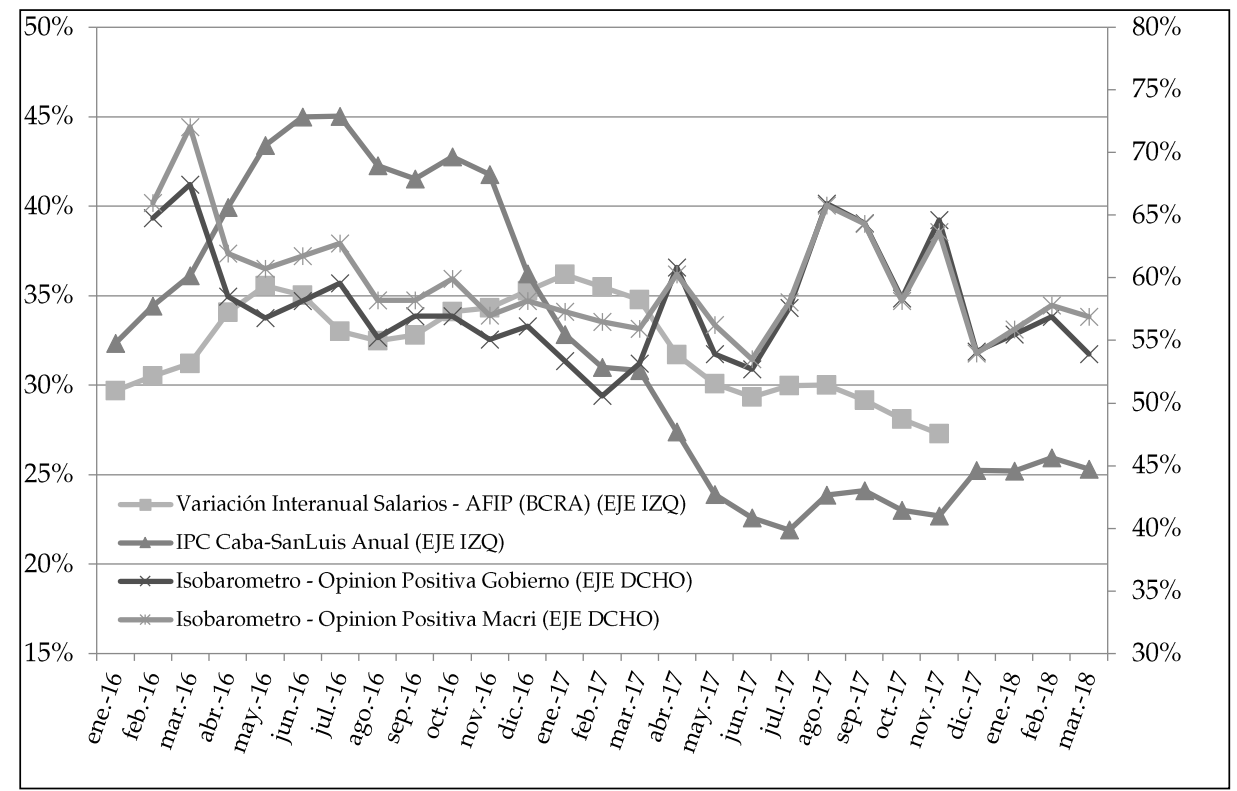

Fuente: elaboración propia en base a datos de las Direcciones de Estadística de CABA y San Luis, BCRA e Isonomía Consultores (2018). 
Así, los meses que precedieron a las elecciones exhibieron una mejora en el desempeño agregado de la economía, una desaceleración de la inflación y una recuperación de los salarios respecto de 2016. El estimador mensual de actividad económica (EMAE) elaborado por el Indec mostró un crecimiento anualizado en torno al 4\% desde mayo de 2017 (Gráfico 3). La inflación anualizada, en niveles cercanos al 36\% anual a diciembre de 2016, se ubicó desde mayo y hasta noviembre en torno al $23 \% .^{2}$ En tanto, los salarios se ajustaron en términos interanuales por encima de la inflación a partir de inicios de 2017 (Gráfico 4). La mejora de los indicadores económicos incidió a su vez en la recuperación de la imagen del presidente y los niveles de aprobación del gobierno. Ambas series, que habían encontrado su piso en marzo de 2017, se recuperaron decisivamente a partir de junio. Las mejoras de la economía y de la opinión pública estuvieron sincronizadas con el calendario electoral, de modo que el trimestre electoral encontró al partido de gobierno en el ápice de la consideración del electorado (Gráficos 3 y 4). En suma, el mejoramiento de la economía en los meses previos a las elecciones tuvo consecuencias políticas virtuosas para el gobierno.

La contracara fue la acumulación de desequilibrios en el frente fiscal y externo. En efecto, para 2017 el déficit primario del sector público se mantuvo en 3,8\% del PBI, al tiempo que el déficit total se ubicó en 6 puntos del producto (Ministerio de Hacienda 2018). El gobierno recurrió al endeudamiento externo para financiar ese déficit, mientras que el Banco Central (BCRA) mantenía tasas de interés positivas en términos reales para evitar presiones sobre el tipo de cambio. La consecuencia de ambas políticas fue un aumento del stock y los servicios de la deuda pública, y el crecimiento exponencial del stock de títulos del BCRA con vencimientos a corto plazo. Para diciembre de 2017 la deuda externa del gobierno (a valor de mercado) había aumentado 35,5\% respecto al mismo mes del año anterior, de 104,6 a 141,8 mil millones de dólares (Indec 2018c). Al mismo tiempo, el stock de títulos de deuda a corto plazo del BCRA, remunerados a una tasa de interés promedio del 25,5\%, se incrementó en términos interanuales en un $60 \%$ en dólares al tipo de cambio oficial (Banco Central de la República Argentina 2018b).

El crecimiento de la economía y la apreciación cambiaria impactaron además en el frente externo. El déficit de la cuenta corriente duplicó a fin de año los valores de diciembre de 2016, llegando 30 mil millones de dólares (Indec). La combinación de estos desarrollos colocó a la Argentina en una situación de vulnerabilidad frente a un eventual endurecimiento de las condiciones de acceso al financiamiento internacional o en caso de que algún evento externo o de política interna coordinara desfavorablemente las expectativas y produjera un desarme de posiciones en pesos. En suma, la contracara de los aspectos políticamente virtuosos de la política económica fue un aumento del stock

2 Estos datos corresponden al promedio simple de los índices de inflación elaborados por las Direcciones de Estadísticas de la Ciudad de Buenos Aires y de la provincia de San Luis. 
de deuda y un deterioro de los frentes fiscal y externo. Sólo después de las elecciones el gobierno se abocaría a tales frentes.

\section{Empoderando a los poderosos: el sector agroexportador en la coalición de Cambiemos}

El gobierno cultivó activamente el apoyo de los sectores económicos que son los ganadores objetivos del cambio de rumbo económico. Un actor clave en este sentido es el sector agroexportador, beneficiados por la estrategia del gobierno de crecer a partir de los sectores con ventajas competitivas estáticas. La importancia del sector se explica también por motivos políticos. En efecto, el conflicto con los productores rurales en 2008 significó el primer revés de importancia para el gobierno del FPV y explica la derrota en las elecciones legislativas de 2009 (De Luca y Malamud 2010). Si bien el FPV pudo recuperarse electoralmente, el "campo" permaneció como un núcleo duro de oposición a sus políticas, cortejado por los partidos de oposición (Freytes 2015b) y electoralmente refractario al FPV (Murillo et al. 2017). De hecho, las zonas agropecuarias votaron masivamente por Cambiemos en 2015, contribuyendo decisivamente al triunfo electoral en segunda vuelta (Freytes y Niedzwiecki 2016).

La política de Cambiemos reflejó la importancia del sector en su coalición social de apoyo. Inicialmente, a través de la devaluación y liberación del tipo de cambio, y la remoción de los impuestos y las restricciones cuantitativas a la exportación de maíz, trigo y carne. El gobierno devolvió además a las asociaciones rurales tradicionales el control del ministerio respectivo. En 2016, el deterioro del frente fiscal lo obligó a revisar la promesa de reducir las retenciones a la exportación de soja, el principal cultivo exportable de Argentina, a razón de un 5\% anual, sustituyéndola por un cronograma de reducción del impuesto del 0,5\% mensual a partir de enero de 2018 (Mira 2016). Según cálculos del sector, el nuevo cronograma implica resignar ingresos fiscales por USD 1000 millones anuales, o 1\% de la recaudación tributaria (La Nación 2017a).

Otra medida que favorece al complejo agroexportador es la eliminación de la obligación de liquidar en el mercado doméstico las divisas producto de la exportación de granos y carnes (Gammacurta 2017). La decisión priva al gobierno de un instrumento para regular la oferta de dólares comerciales y deja en consecuencia a la política económica más vulnerable frente a un eventual endurecimiento del frente externo. Finalmente, en noviembre de 2017, el presidente de la asociación rural más conservadora e identificada con los grandes propietarios, la Sociedad Rural Argentina (SRA), asumió la conducción del Ministerio de Agricultura. Estas decisiones de política pública fueron electoralmente eficaces. Como veremos en la sección 4, en las elecciones de octubre Cambiemos volvió a hacerse fuerte en la zona central del país, donde está implantada la agricultura de exportación. 


\section{Compensando a los perdedores: reforma previsional y asistencia social}

La estrategia del gobierno durante 2016 había consistido en compensar a las organizaciones sindicales como válvula de control de la movilización social (Vommaro y Gené 2017). Respecto al sector informal, mantuvo las políticas sociales sancionadas durante el gobierno anterior, expandiéndolas en algunos casos, y aumentó el ingreso de los adultos mayores (Niedzwiecki y Pribble 2017). En este sentido, la principal reforma de política social de Macri antes de las elecciones ocurrió en el sector previsional. A mediados de 2016, el gobierno implementó la Pensión Universal a la Vejez, una transferencia del 80\% de la pensión mínima que llegaba a todos los mayores de 65 años sin cobertura, independientemente de sus contribuciones anteriores. Esto produjo en 2017 un incremento marginal de los niveles de cobertura (del $97 \%$ al $98 \%$ de los adultos mayores) (Presidencia de la Nación Argentina 2017: 5). Además, la ley incorporó una Reparación Histórica para aquellos jubilados y pensionados del sistema contributivo, cuyas transferencias no habían sido actualizadas por inflación. A cambio de la actualización de haberes, los jubilados debían desistir de iniciar acciones legales. Estas propuestas suponían un incremento de popularidad para el presidente y un posible desfinanciamiento del sistema a futuro (ver apartado 5). A los fines de que esta ley fuera aprobada en la legislatura, el gobierno acordó con las provincias un plan de pago para devolver los fondos coparticipables que habían sido destinados a la Administración Nacional de la Seguridad Social (Anses) (Niedzwiecki y Pribble 2017).

A corto plazo, la reforma expandió las prestaciones del sistema previsional, beneficiando a adultos mayores vulnerables sin suficientes contribuciones, así como también a sectores medios que habían visto sus ingresos afectados por la inflación y que tenían acceso a abogados para iniciar un juicio en contra del Estado. Además, la reforma benefició a las provincias, sobre todo a las periféricas que son las más dependientes de las transferencias federales, al devolver parte de los fondos de la coparticipación. Sin embargo, a largo plazo, la devolución de los fondos coparticipables y la reparación histórica contribuyen a la desfinanciación del sistema previsional. Estas medidas estuvieron parcialmente financiadas por el blanqueo de capitales incluido en la misma ley, pero este ingreso es extraordinario y no continuo como son las transferencias por jubilaciones (Etchemendy 2017). Este riesgo llevó al gobierno a modificar la fórmula de ajuste para reducir el gasto luego de las elecciones.

El sector informal también se vio compensado por Cambiemos durante 2017, a través de la continuación de las políticas de asistencia social de la gestión anterior. Esta fue una decisión astuta por parte del gobierno, dada la alta visibilidad y popularidad de los programas de transferencia condicionada (Niedzwiecki 2016, 2018). La Asignación Universal por Hijo (AUH) existe desde el 2009 y es una prestación mensual otorgada a familias (priorizando a la madre) de bajos recursos por cada hijo menor de 18 años (\$1493) y por hijos 
con discapacidad $(\$ 4869) .{ }^{3}$ La reciben personas desocupadas, no registradas (sin aportes), que trabajan en el servicio doméstico y personas inscriptas en otros programas nacionales compatibles con la AUH. Confirmando el argumento de este trabajo en relación con la política expansiva del gobierno de cara a las elecciones, Macri aumentó la población que recibe la AUH a los monotributistas sociales, expandiendo así su cobertura (Arza 2016). Según datos oficiales, ésta aumentó un 7\% en dos años, de 3,68 millones de niños en 2015 a 3,94 millones en noviembre de 2017 (Presidencia de la Nación Argentina 2017: 5). Además, previo a las elecciones la administración de Cambiemos preservó la ley aprobada por el gobierno anterior para la actualización del monto de la asignación dos veces por año, lo que no evitó su depreciación en términos reales (Niedzwiecki y Pribble 2017). La combinación de una macro expansiva, el mantenimiento de los programas sociales y la desaceleración de la inflación tuvieron a su turno un impacto sobre la medición de pobreza. En efecto, según las cifras del Indec, entre el segundo semestre de 2016 y el segundo semestre de 2017, hubo una caída interanual de alrededor de 5 puntos porcentuales, de 30,3 a 25,7\%, mientras que la indigencia se redujo del 6,1 a 4,8\% de la población (Indec 2018b).

\section{CONTEXTO POLÍTICO: CAMBIEMOS EN EL GOBIERNO}

\section{Entre la regeneración institucional y la demanda de orden}

La política económica expansiva durante el año electoral y la compensación a los perdedores no fueron los únicos factores que explican el apoyo al gobierno en la opinión pública. Como señalamos en la introducción, Mauricio Macri llegó a la presidencia en un contexto de agotamiento y rechazos sociales amplios de la experiencia kirchnerista. Un vector central de la interpelación de Cambiemos al electorado y a la sociedad consistió en presentarse como la antítesis absoluta del período anterior $y$, una vez en el gobierno, como la garantía del no retorno a ese período "oscuro" del pasado inmediato. Esta estrategia se verificó en la construcción pública de un estilo de liderazgo presidencial dialógico y abierto a la admisión de errores; en la propuesta de un ethos individualista, emprendedor y meritocrático como reemplazo de la matriz militante y estadocéntrica que había caracterizado al kirchnerismo (Vommaro 2017b: 7); y en la interpelación al electorado en términos ya no de la satisfacción de sus necesidades inmediatas sino de la representación de sus aspiraciones de ascenso social (Burdman 2017). En suma, Cambiemos hizo de la modernización de la gestión y la individualización y privatización de la vida pública los ejes de su interpelación cultural (Vommaro 2017b; Seman 2017). El discurso de Cambiemos no sólo logró una amplia identificación por parte de los sectores medios urbanos, sino que, en

Anses. Asignación Universal Por Hijo. Recuperado el 20 de marzo de 2018 de https:/ /www.anses.gob.ar/ informacion/montos-de-asignacion-universal-por-hijo-y-por-embarazo-para-proteccion-social/ 
un contexto de creciente fragmentación de los sectores populares, tuvo también eco en aquellos segmentos menos dependientes de las transferencias estatales para la reproducción de su vida cotidiana (Zarazaga 2017; Seman 2017).

En este contexto, la corrupción fue uno de los temas de la agenda pública con rendimientos duraderos y constantes para el gobierno. Una serie de casos de gran visibilidad mediática, vinculados en su mayoría con contratos de obra pública, y que involucraban en algunos casos a la expresidenta Cristina Kirchner y su familia, contribuyeron a mantener el tema en el centro de la escena pública. La memoria de la "corrupción $\mathrm{K}^{\text {", }}$ reproducida y alimentada por los medios afines, se convirtió así en un reservorio permanente de apoyos sociales a los que el gobierno pudo recurrir en cada coyuntura adversa. Y los casos que involucran a altos funcionarios del actual gobierno, incluyendo el presidente y su familia, en potenciales conflictos de intereses entre sus roles privados y públicos, o la revelación de que varias de ellos mantienen o habían mantenido parte de su patrimonio en cuentas off-shore, no llegaron a hacer mella en esta identificación. Así, en marzo de 2018, un 83\% de la opinión pública (incluyendo una porción de votantes del FPV) caracterizaba al anterior gobierno del FPV como corrupto, mientras que sólo el 36\% caracterizaba al gobierno de Cambiemos de la misma manera (Isonomía Consultores 2018).

En el enjuiciamiento de los hechos de corrupción de la administración anterior incidió también el comportamiento estratégico de los jueces federales, que vieron en la gestión de esas causas una vía expedita para ganarse la buena voluntad de la nueva administración y diferir quizás una revisión más profunda del Poder Judicial. Este comportamiento se aceleró luego del triunfo del gobierno en las elecciones de octubre. Luego de ellas, la Justicia Federal avanzó en el enjuiciamiento de funcionarios del gobierno anterior, ya no exclusivamente por desmanejo de fondos públicos, sino por decisiones tomadas en el ejercicio del gobierno. Desde octubre a diciembre, la justicia federal dictó la prisión preventiva del exministro de Obras Públicas Julio de Vido; del exvicepresidente de la Nación Amado Boudou; del exsecretario de Legal y Técnica Carlos Zannini; y de la expresidenta Cristina Kirchner. En los dos últimos casos, la decisión implicó enjuiciar al gobierno precedente por decisiones de política exterior tomadas en el ejercicio legítimo de sus competencias constitucionales y ratificadas por el Congreso. ${ }^{4}$ Mientras que la exmandataria estaba para entonces protegida por fueros legislativos, los tres primeros fueron encarcelados. El dictado de estas prisiones se vio facilitado por una reintepretación de la doctrina previa respecto de qué constituye un riesgo de fuga, que aplicó la figura a todos los exfuncionarios, ampliando así al máximo el margen de discrecionalidad de los

4 La prisión preventiva de la expresidenta se dio en la causa por la firma de un memorándum de entendimiento con Irán para destrabar la investigación del atentado contra la sede de la mutual judía de la AMIA, ocurrido en 1994. El tema adquirió voltaje político a raíz de las denuncias del fiscal Alberto Nissman, quien fue encontrado muerto en su departamento en enero de 2015 un día antes de testificar en el Congreso. El hecho conmocionó a la opinión pública, agitó las pasiones políticas y fue un suceso clave de ese año electoral. Ver en este sentido Murillo, Mangonnet y Rubio (2015). 
jueces (Pagni 2017). El comportamiento estratégico y discrecional de la justicia sugiere que la agenda de la transparencia y del control republicano discurre todavía en la Argentina sobre bases institucionales endebles.

A la par que comprometido con la eficiencia administrativa y la transparencia, Cambiemos se presentó como un gobierno del orden, endureciendo su discurso contra el crimen y ofreciendo un respaldo incondicional al accionar de las fuerzas de seguridad, incluso con la finalidad de reprimir la protesta social. Los riesgos asociados con esta política fueron puestos en escena dramáticamente con la muerte de Santiago Maldonado, quien fue desaparecido mientras participaba de una ocupación de tierras en la provincia de Chubut, en apoyo al reclamo de tierras ancestrales por parte de la comunidad mapuche. El reclamo por su desaparición fue intenso en los meses previos a las elecciones, incluyendo varias marchas multitudinarias en la Plaza de Mayo convocadas por la familia con el apoyo de organismos de derechos humanos. El hecho fue leído a la luz de dichos y decisiones del gobierno cuya consecuencia objetiva fue aumentar los costos de la movilización hasta el límite de no garantizar la integridad física de las personas.

La entidad que adquirió el caso de Santiago Maldonado se explica al ser puesto en serie con otro hecho relevante del año político: en mayo, la Corte Suprema dictó un fallo en el caso Muiña, que extendía a los condenados por crímenes de lesa humanidad durante la última dictadura militar los beneficios de la ley del $2 \times 1 .^{5}$ El fallo de la corte resonó con declaraciones previas de miembros del gobierno proponiendo una lectura revisionista de lo ocurrido durante la última dictadura militar, reflejando que para los actuales dirigentes la lucha por la recuperación de la democracia no forma parte de sus experiencias formativas, y motivando una fuerte movilización de los organismos de derechos humanos (Leiras 2017). El episodio se cerró con una ley sancionada con una mayoría abrumadora por el Congreso, que excluye esos crímenes de la aplicación del 2 $x 1$.

\section{Cambiemos como gobierno minoritario y la fragmentación del peronismo}

Además de la administración temporal del ajuste y los recursos simbólicos del gobierno, un hecho político crucial para entender el éxito electoral del gobierno es la dificultad de las distintas facciones del peronismo para resolver la disputa por el liderazgo y la orientación del partido luego de la derrota electoral de 2015. La fragmentación del peronismo tuvo a su vez importantes consecuencias para el ejercicio del gobierno por parte de Cambiemos. En efecto, desde 2015 el gobierno era decididamente minoritario tanto en el Congreso como en el 
gobierno de las provincias (Freytes y Niedzwiecki 2016). Esta situación obligó a Macri a negociar con la oposición los paquetes de leyes más importantes. El gobierno tuvo para ello menos dificultades de lo que una lectura lineal de la relación de fuerzas inicial en el Congreso hacía prever. Cambiemos pudo explotar las divisiones del peronismo para negociar las leyes importantes con los sectores no kirchneristas y con los legisladores de provincias peronistas con obligaciones de gobierno. Pudo así utilizar los recursos asociados con el control del Ejecutivo para ampliar sus aliados provinciales a través de la distribución de recursos federales discrecionales y de obra pública, siguiendo la estrategia utilizada por gobiernos anteriores. Ambas dinámicas se reflejaron en el Congreso, con la conformación de un bloque justicialista separado del FPV en la Cámara Baja, y la articulación en el Senado de un bloque justicialista mayoritario abiertamente crítico de la expresidenta. Como resultado, en sus dos primeros años en la Casa Rosada, el gobierno logró aprobar más del 70\% de sus proyectos de ley (Serra 2018a).

Las distintas facciones del peronismo se mantuvieron divididas durante las elecciones de 2017 entre aquellos sectores que impugnaban el liderazgo de Cristina Kirchner y aquellos que se referenciaban en la expresidenta. Las pujas internas del peronismo se pusieron en juego en la provincia de Buenos Aires. Esa elección adquirió dimensión nacional por la magnitud del electorado $(40 \%$ del padrón nacional), por tratarse de la provincia que concentra mayor volumen absoluto de voto peronista y porque allí la expresidenta Kirchner iba a competir por una banca para el Senado de la Nación con un candidato relativamente ignoto de Cambiemos, el ministro de Educación Esteban Bullrich. Para muchos actores del peronismo, el triunfo de María Eugenia Vidal en 2015 había sido una contingencia histórica en una provincia gobernada por el peronismo durante casi tres décadas. La elección legislativa suponía una chance para revertir esa anomalía.

La elección de la provincia ejemplificó además todas las opciones que se les presentaban a los actores del polo peronista: por un lado, la figura de la expresidenta encarnaba la opción kirchnerista pura, centrada en la crítica al modelo económico del gobierno. Por otro lado, el exministro del Interior de Cristina Kirchner, Florencio Randazzo, se postuló para competir con ella en las primarias del PJ, en nombre de la apertura de un proceso de autocrítica y discusión interna, y apostando a capitalizar dentro del peronismo el rechazo que la figura de la exmandataria concitaba en segmentos importantes del electorado. Por último, la opción de renovar al peronismo "desde afuera" estaba representada por Sergio Massa, con su fuerza 1Pais. No obstante, la primaria que Randazzo demandaba no llegó a producirse: en una maniobra inesperada, Cristina Kirchner renunció a la etiqueta del PJ y se presentó a través de un instrumento electoral ad hoc, Unidad Ciudadana. Esto implicó que en la elección general se presentaran tres opciones de origen peronista. La jugada tuvo consecuencias sistémicas en cómo se computarían los votos a nivel nacional, 
y terminó de consolidar la imagen de un gobierno claramente ganador en las elecciones de medio término.

\section{LAS ELECCIONES INTERMEDIAS DE 2017 Y EL TRIUNFO ELECTORAL DE CAMBIEMOS}

El gobierno salió claramente fortalecido de las elecciones legislativas del 2017 para renovar un tercio de la Cámara de Senadores y la mitad de la Cámara de Diputados, consolidándose así como la primera fuerza nacional. ${ }^{6}$ A nivel nacional, Cambiemos obtuvo el $42 \%$ de los votos, duplicando al kirchnerismo, la segunda fuerza electoral (Tabla 1), y alcanzando el porcentaje logrado por "los presidentes que lideraron los tres «ciclos largos» de la democracia argentina: Raúl Alfonsín, Carlos Menem y Néstor Kirchner" (Natanson 2017: 4). Al mismo tiempo, la magnitud del triunfo de Cambiemos se vio amplificada por la división del peronismo. Con $20,8 \%$ de los votos a nivel nacional, el polo kirchnerista quedó instalado en segundo lugar, esencialmente por los cerca de 3,4 millones de votos que la lista encabezada por Cristina Kirchner obtuvo en Buenos Aires. El PJ, en tanto, obtuvo alrededor del $16 \%$ de los votos a nivel nacional. ${ }^{7}$

Tabla 1. Resultado de elecciones a diputados nacionales agregados a nivel nacional.

\begin{tabular}{lcc}
\hline \multicolumn{1}{c}{ Partido } & Votos & $\%$ \\
\hline Cambiemos & 10.261 .237 & $41,7 \%$ \\
UC-FPV & 5.122 .624 & $20,8 \%$ \\
PJ & 3.988 .746 & $16,2 \%$ \\
1País & 1.413 .543 & $5,8 \%$ \\
FIT & 1.067 .522 & $4,3 \%$ \\
Provinciales & 652.771 & $2,7 \%$ \\
Otros & 2.054 .632 & $8,4 \%$ \\
\hline
\end{tabular}

Fuente: elaboración propia en base a datos de la Dirección Nacional Electoral, disponibles en https:/ / www. argentina.gob.ar/resultadoselecciones-2017

Todas las provincias eligieron diputados nacionales y ocho también eligieron senadores de la Nación. Dos meses antes, en agosto de 2017, se habían realizado las PASO (Primarias Abiertas, Simultáneas y Obligatorias) para seleccionar los candidatos que competirían en la elección general (CIPPEC 2017).

Para llegar a este resultado agregamos los votos a nivel nacional utilizando las etiquetas partidarias a nivel de distritos. 
Tabla 2. Resultado de elecciones a diputado nacional por provincia

\begin{tabular}{|c|c|c|c|c|c|c|c|}
\hline Provincia & REGIóN & $\begin{array}{c}\text { \% Voto } \\
\text { CAMBIEMos } \\
\text { (A) }\end{array}$ & $\begin{array}{l}\text { Otra FuERZA } \\
\text { Más Votada } \\
\text { (B) }\end{array}$ & $\begin{array}{l}\text { Otra Fuer- } \\
\text { Za MÁs } \\
\text { Votada (B) }\end{array}$ & $\begin{array}{l}\% \text { Vото } \\
\text { (B) }\end{array}$ & $\begin{array}{c}\text { DIFERENCIA } \\
\text { A FAVOR/EN } \\
\text { CONTRA } \\
\text { CAMBIEMOS } \\
\text { (A-B) }\end{array}$ & $\begin{array}{l}\text { PARTIDO } \\
\text { GobIERnO }\end{array}$ \\
\hline Jujuy & Noroeste & $51,7 \%$ & $\begin{array}{l}\text { Frente Justi- } \\
\text { cialista }\end{array}$ & PJ-FPV & $19,8 \%$ & $32,0 \%$ & $\begin{array}{c}\text { Cambiemos } \\
\text { (UCR) }\end{array}$ \\
\hline Corrientes & Noreste & $55,4 \%$ & $\begin{array}{l}\text { Juntos Pode- } \\
\text { mos Mas }\end{array}$ & PJ-FPV & $25,6 \%$ & $29,8 \%$ & $\begin{array}{c}\text { Cambiemos } \\
\text { (EC) }\end{array}$ \\
\hline CABA & Centro & $51,0 \%$ & $\begin{array}{l}\text { Unidad Por- } \\
\text { teña }\end{array}$ & PJ-FPV & $21,7 \%$ & $29,2 \%$ & $\begin{array}{l}\text { Cambiemos } \\
\text { (PRO) }\end{array}$ \\
\hline Mendoza & Centro & $45,7 \%$ & $\begin{array}{l}\text { Somos Men- } \\
\text { doza }\end{array}$ & PJ-FPV & $25,4 \%$ & $20,3 \%$ & $\begin{array}{c}\text { Cambiemos } \\
\text { (UCR) }\end{array}$ \\
\hline Córdoba & Centro & $48,5 \%$ & $\begin{array}{l}\text { Unión por } \\
\text { Córdoba }\end{array}$ & PJ & $30,5 \%$ & $18,0 \%$ & $\mathrm{UPC}(\mathrm{PJ})$ \\
\hline Entre Ríos & Centro & $53,0 \%$ & $\begin{array}{l}\text { Frente Justi- } \\
\text { cialista Somos } \\
\text { Entre Ríos }\end{array}$ & PJ-FPV & $38,0 \%$ & $15,1 \%$ & FPV \\
\hline Santa Cruz & Sur & $43,9 \%$ & $\begin{array}{l}\text { Frente Para La } \\
\text { Victoria }\end{array}$ & FPV & $32,0 \%$ & $12,0 \%$ & FPV \\
\hline Santa Fe & Centro & $37,8 \%$ & $\begin{array}{l}\text { Frente Justi- } \\
\text { cialista }\end{array}$ & PJ-FPV & $25,9 \%$ & $11,9 \%$ & $\begin{array}{l}\text { FPCS (PS- } \\
\text { UCR) }\end{array}$ \\
\hline Neuquén & Sur & $28,2 \%$ & $\begin{array}{l}\text { Movimiento } \\
\text { Popular Neu- } \\
\text { quino }\end{array}$ & Provincial & $21,4 \%$ & $6,8 \%$ & $\begin{array}{l}\text { MPN (Pro- } \\
\text { vincial) }\end{array}$ \\
\hline $\begin{array}{l}\text { Buenos } \\
\text { Aires }\end{array}$ & Centro & $42,2 \%$ & $\begin{array}{l}\text { Unidad Ciu- } \\
\text { dadana }\end{array}$ & FPV & $36,3 \%$ & $5,9 \%$ & $\begin{array}{c}\text { Cambiemos } \\
\text { (PRO) }\end{array}$ \\
\hline Salta & Noroeste & $30,2 \%$ & $\begin{array}{l}\text { Frente Unidad } \\
\text { y Renovación }\end{array}$ & PJ & $24,4 \%$ & $5,8 \%$ & FPV (PJ) \\
\hline Chaco & Noreste & $41,8 \%$ & $\begin{array}{l}\text { Frente Chaco } \\
\text { Merece Más }\end{array}$ & PJ-FPV & $39,6 \%$ & $2,2 \%$ & FPV (PJ) \\
\hline La Rioja & Noroeste & $44,8 \%$ & $\begin{array}{l}\text { Frente } \\
\text { Justicialista } \\
\text { Riojano }\end{array}$ & PJ-FPV & $44,1 \%$ & $0,6 \%$ & FPV (PJ) \\
\hline La Pampa & Centro & $45,4 \%$ & Justicialista & PJ & $45,4 \%$ & $0,0 \%$ & PJ \\
\hline $\begin{array}{l}\text { T. del } \\
\text { Fuego }\end{array}$ & Sur & $29,8 \%$ & $\begin{array}{l}\text { Frente } \\
\text { Ciudadano y } \\
\text { Social }\end{array}$ & FPV & $30,0 \%$ & $-0,2 \%$ & FPV \\
\hline Chubut & Sur & $31,2 \%$ & $\begin{array}{l}\text { Frente Chubut } \\
\text { Para Todos }\end{array}$ & (PJ) & $33,2 \%$ & $-2,1 \%$ & UCST (PJ) \\
\hline Catamarca & Noroeste & $41,9 \%$ & $\begin{array}{l}\text { Frente Justi- } \\
\text { cialista Para } \\
\text { La Victoria }\end{array}$ & PJ-FPV & $47,8 \%$ & $-6,0 \%$ & FPV (PJ) \\
\hline Misiones & Noreste & $33,6 \%$ & $\begin{array}{l}\text { Frente Ren- } \\
\text { ovador de la } \\
\text { Concordia }\end{array}$ & Provincial & $42,8 \%$ & $-9,1 \%$ & $\begin{array}{l}\text { FRCS (Pro- } \\
\text { vincial) }\end{array}$ \\
\hline San Luis & Centro & $43,0 \%$ & $\begin{array}{l}\text { Frente Unidad } \\
\text { Justicialista } \\
\text { San Luis }\end{array}$ & PJ-FPV & $55,0 \%$ & $-12,0 \%$ & $\mathrm{CF}(\mathrm{PJ})$ \\
\hline Tucumán & Noroeste & $32,6 \%$ & $\begin{array}{l}\text { Frente Justi- } \\
\text { cialista Por } \\
\text { Tucumán }\end{array}$ & PJ & $46,9 \%$ & $-14,3 \%$ & FPV (PJ) \\
\hline
\end{tabular}




\begin{tabular}{|c|c|c|c|c|c|c|c|}
\hline Provincia & REGIÓN & $\begin{array}{l}\text { \% Voto } \\
\text { CAMbiemos } \\
\text { (A) }\end{array}$ & $\begin{array}{c}\text { Otra Fuerza } \\
\text { Más VotAda } \\
\text { (B) }\end{array}$ & $\begin{array}{l}\text { Otra Fuer- } \\
\text { ZA MÁs } \\
\text { Votada (B) }\end{array}$ & $\begin{array}{l}\text { \% Vото } \\
\text { (В) }\end{array}$ & $\begin{array}{c}\text { DIFERENCIA } \\
\text { A FAVOR/EN } \\
\text { CONTRA } \\
\text { CAMBIEMOS } \\
(\mathrm{A}-\mathrm{B})\end{array}$ & $\begin{array}{l}\text { PARTIDO } \\
\text { GobIERNo }\end{array}$ \\
\hline Río Negro & Sur & $32,0 \%$ & $\begin{array}{l}\text { Frente Para La } \\
\text { Victoria }\end{array}$ & PJ-FPV & $49,4 \%$ & $-17,4 \%$ & $\begin{array}{l}\text { AJSRN (Pro- } \\
\text { vincial) }\end{array}$ \\
\hline San Juan & Noroeste & $31,5 \%$ & Frente Todos & PJ & $53,7 \%$ & $-22,2 \%$ & FPV (PJ) \\
\hline Formosa & Noreste & $36,6 \%$ & $\begin{array}{l}\text { Frente de la } \\
\text { Victoria }\end{array}$ & PJ-FPV & $61,9 \%$ & $-25,3 \%$ & FPV (PJ) \\
\hline $\begin{array}{l}\text { S. del } \\
\text { Estero }\end{array}$ & Noroeste & $17,3 \%$ & $\begin{array}{l}\text { Frente Cívico } \\
\text { Por Santiago }\end{array}$ & Provincial & $70,1 \%$ & $-52,8 \%$ & FCSE \\
\hline
\end{tabular}

Cambiemos fue la única coalición que logró presentar alianzas congruentes (conformadas por los mismos partidos, el PRO, la UCR y la CC) en 22 de las 24 provincias (CIPPEC 2017: 11). El oficialismo nacional ganó en 13 de las 24 provincias, ampliando su implantación territorial respecto de la segunda vuelta electoral de 2015, mientras que la oposición ganó en las 11 restantes (Tabla 1 y Gráfico 5). Cambiemos se impuso por mayor margen en las provincias donde controla el gobierno provincial (Jujuy, Corrientes, CABA y Mendoza), en las provincias centrales donde está implantada la agricultura de exportación o su sector de servicios (CABA, Córdoba, Entre Ríos, Santa Fe y Buenos Aires), y allí donde el peronismo se presentó dividido (Córdoba, Buenos Aires, Salta y Neuquén) (Tabla 1 y Gráfico 6). Estos resultados guardan continuidad con las elecciones de 2015, con Cambiemos logrando mejores números en la zona central del país, con perfil agropecuario, y el peronismo con mejores resultados en las provincias periféricas (Freytes y Niedzwiecki 2016). Sin embargo, como muestra el Gráfico 5, la novedad de esta elección fue la expansión territorial del voto de Cambiemos hacia las provincias periféricas de Jujuy, Corrientes, Chaco, La Rioja, Salta, Neuquén y Santa Cruz. Otro indicador del fortalecimiento electoral de Cambiemos es la mejora de su performance electoral respecto de las elecciones legislativas de 2015: la coalición de gobierno aumentó el número de votos obtenidos en 20 de las 24 provincias, y el porcentaje de votos obtenidos en 19 de las 24. Las mayores ganancias (más de diez puntos porcentuales) ocurrieron en provincias periféricas (Gráfico 7$){ }^{8}$ 
Gráfico 5. Partido más votado por provincia

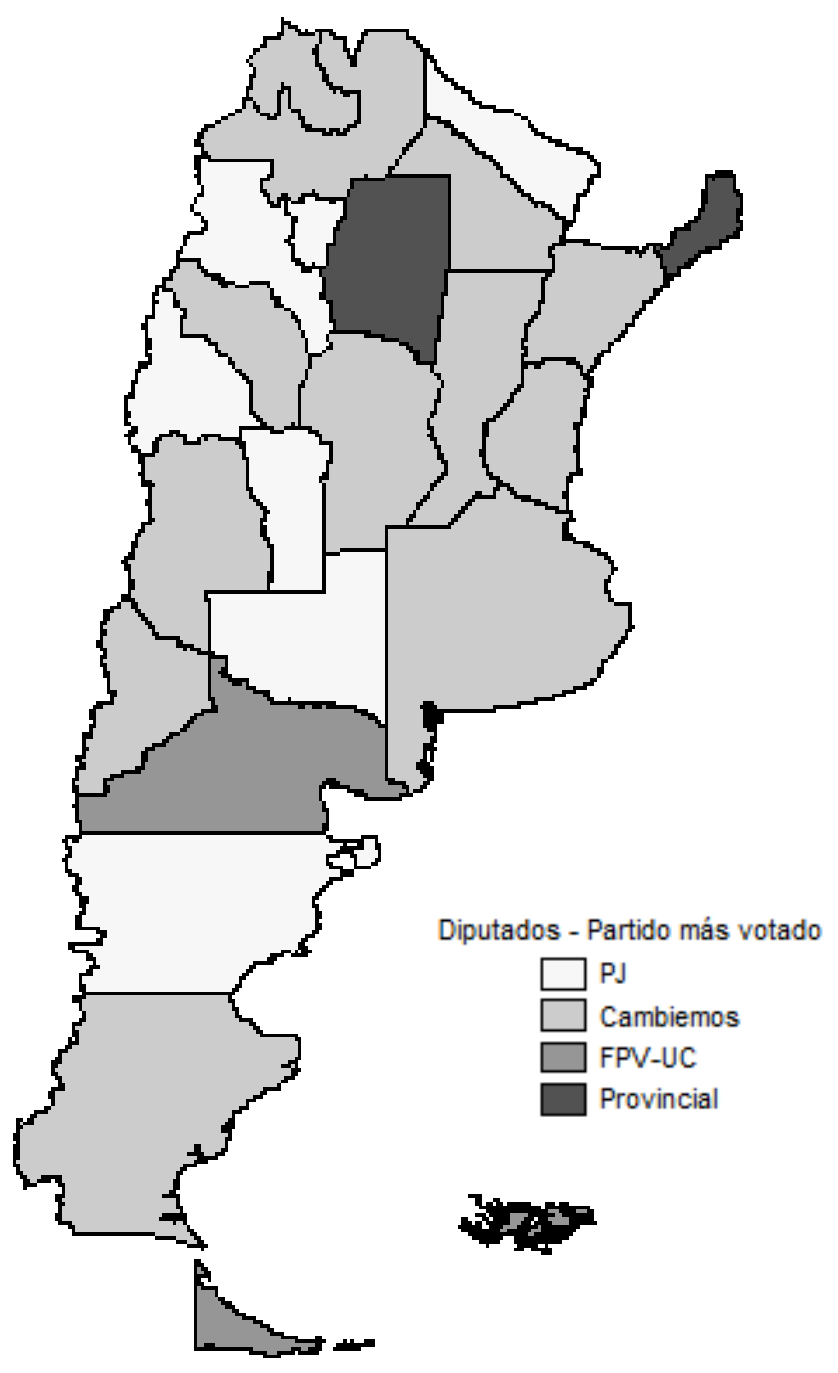

Fuente: elaboración propia en base a datos de la Dirección Nacional electoral, accesibles en: https: / www.argentina.gob.ar/resultadoselecciones-2017 
Gráfico 6. Diferencia a favor/en contra de Cambiemos por provincia

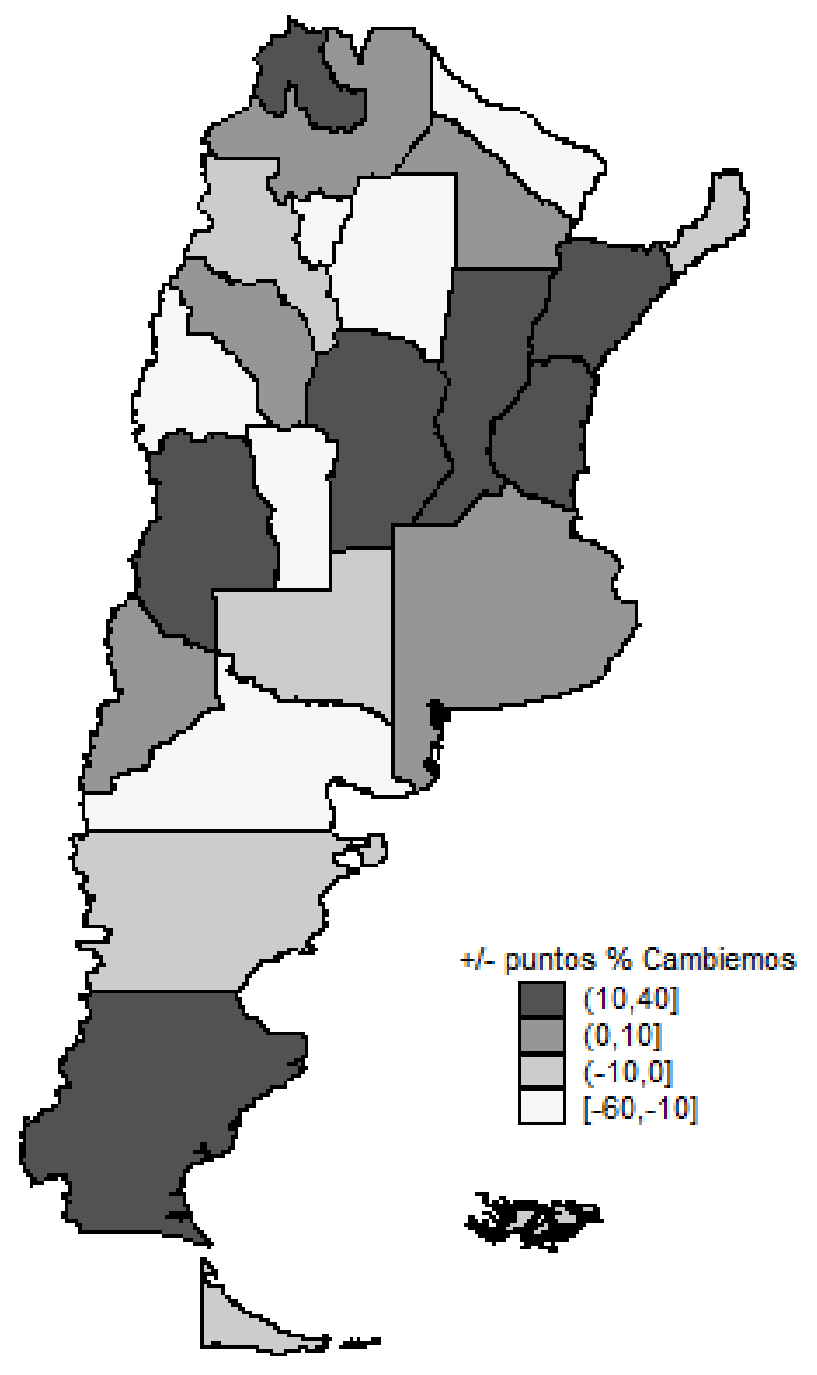

Fuente: elaboración propia en base a datos de la Dirección Nacional electoral, accesibles en: https: / /www.argentina.gob.ar/resultadoselecciones-2017 
Gráfico 7. Voto por Cambiemos comparado con elección legislativa 2015 (+/- puntos \%)

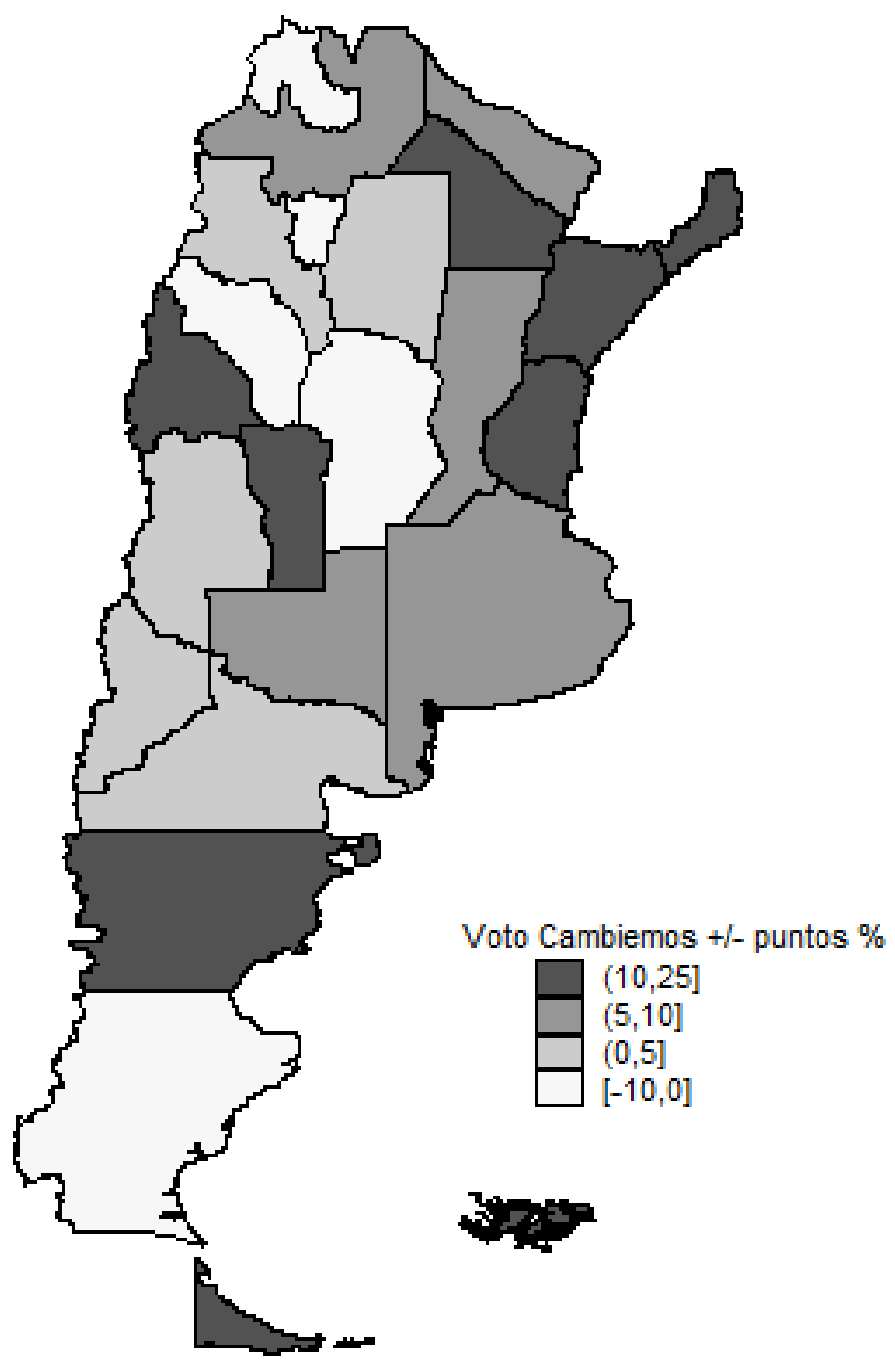

Fuente: elaboración propia en base a datos de la Dirección Nacional electoral, accesibles en: https: / /www.argentina.gob.ar/resultadoselecciones-2017

Cambiemos avanzó también en esta elección sobre distritos gobernados por la oposición, incluyendo provincias donde históricamente predominó la centroderecha peronista, como Salta, La Rioja, La Pampa y San Luis, logrando así migrar votantes afines al peronismo antikirchernista. Este resultado muestra quizás los límites para una opción de centroderecha dentro del peronismo mientras Cambiemos siga ocupando firmemente ese espacio en la política nacional (Calvo 2017). Lejos de ordenar la interna peronista, el resultado de la 
elección puso así en evidencia los dilemas que ese espacio enfrenta de cara a su reconstrucción. Por un lado, la expresidenta demostró que sigue siendo la dirigente con mayor caudal electoral, lo que en la práctica implica un freno a la posibilidad de un viraje centrista. Por otro lado, su figura sigue concitando elevados niveles de rechazo en segmentos mayoritarios de los electorados metropolitanos de clase media a los que el PJ debería reconquistar para mejorar sus chances en elecciones presidenciales.

Tabla 3. Composición de la Cámara de Diputados y Senadores por bloques

\begin{tabular}{lcccc}
\hline \multicolumn{1}{c}{ Bloque } & $\begin{array}{c}\text { Diputados } \\
(2015-2017)\end{array}$ & $\begin{array}{c}\text { Diputados } \\
(2017-2019)\end{array}$ & $\begin{array}{c}\text { SEnAdores } \\
(2015-2017)\end{array}$ & $\begin{array}{c}\text { SenAdores } \\
(2017-2019)\end{array}$ \\
\hline Cambiemos & $86^{*}$ & 107 & $15^{*}$ & 24 \\
UC-FPV & 75 & 67 & 18 & 10 \\
PJ & 35 & 40 & 25 & 23 \\
Izquierda & 4 & 3 & - & - \\
Massismo (1Pais) & 38 & 21 & 1 & - \\
Otros & 19 & 19 & 14 & 15 \\
\hline
\end{tabular}

*Bancas correspondientes al Pro y la UCR agrupadas.

Fuente: elaboración propia en base a datos publicados por La Nación. Disponibles online: https:/ /www.lanacion.com.ar/2077311-una-fuerte-expansion-oficialista-en-el-congreso-sin-mayorias

El resultado electoral impactó a su vez sobre la distribución de poder institucional. Después de las elecciones, Cambiemos sumó 21 bancas, consolidándose como la primera minoría con 107 (de 257) escaños. El Frente para la Victoria quedó en segundo lugar con 67 bancas (perdiendo ocho) y el peronismo no kirchnerista ganó 5 bancas, sumando 40 lugares. A pesar de estos cambios, el gobierno no alcanzó a tener quorum propio, con lo cual es esperable que continúe la política de negociaciones de los dos primeros años del gobierno. En la Cámara de Senadores, Cambiemos y el Partido Justicialista quedaron en una situación de paridad, con 24 y 23 bancas respectivamente (de un total de 72 escaños), tras sumar 9 bancas el primero y perder 3 bancas el segundo. El kirchnerismo, en tanto, perdió ocho de las diez bancas que puso en juego (La Nación 2017b). De esta manera, el Senado se convirtió en el ámbito clave de articulación del poder institucional del peronismo federal. 


\section{DESPUÉS DE LAS ELECCIONES: LAS REFORMAS IMPOSITIVA, PREVISIONAL Y LABORAL EN EL CIERRE DEL AÑO}

La resolución de las elecciones de medio término marcó un punto de inflexión en la gestión de Cambiemos. Resuelto el test electoral y fortalecido por el resultado, el gobierno se abocó a resolver las inconsistencias acumuladas, lo que supuso impulsar un pacto fiscal con las provincias, una reforma previsional para revisar la fórmula de ajuste de jubilaciones y asignaciones sociales, y un intento frustrado de avanzar con la reforma laboral. En los últimos días del año, el gobierno produjo además una devaluación y la revisión de las metas de inflación. La medida supuso un reconocimiento tácito de los problemas en el frente externo, de la preocupación de sectores empresariales por la pérdida de competitividad externa y del impacto de las altas tasas de interés sobre el nivel de actividad.

El gobierno pudo avanzar con parte de esta agenda gracias a la cooperación del peronismo de las provincias pero debió enfrentar a una oposición movilizada en contra de los ajustes. Los acontecimientos del último trimestre del año son así reveladores de los trade-offs que enfrenta Cambiemos entre la sustentabilidad política y económica del gobierno. En efecto, la administración no pudo eludir los costos políticos de estas medidas. El pasaje del paquete de leyes en el Congreso fue acompañado por intensas protestas y una escalada del accionar represivo de las fuerzas de seguridad, lo que configuró un escenario de violencia en las calles, provocando una apreciable caída de la popularidad del gobierno en el último mes del año (Gráficos 1 y 2).

\section{Reformas impositiva y previsional}

En noviembre, el gobierno convocó a los gobernadores para celebrar un nuevo pacto fiscal. Los puntos principales del acuerdo eran los siguientes: los gobernadores debían renunciar a los juicios contra el Estado nacional por liquidación de regalías y transferencias de cajas previsionales, y comprometerse con la reducción de impuestos provinciales y la contención del gasto mediante una ley de responsabilidad fiscal. A cambio, el Estado nacional derogaría, entre otros, el artículo 104 del Impuesto a las Ganancias, que excluía de la coparticipación al 36\% de lo recaudado, destinándolo al Fondo del Conurbano Bonaerense (10\%), y a la ANSES (20\%). Ese impuesto pasaría a ser coparticipable en su totalidad, lo que representaba una ganancia para las provincias. La pérdida de ingresos de la ANSES sería compensada por la asignación del $100 \%$ de lo recaudado por el impuesto al cheque (contra un $70 \%$ previo), que sería prorrogado (Obarrio 2017a). De acuerdo con una estimación, el paquete impositivo implicaba una pérdida de ingresos de 1,1\% del PBI para el Tesoro Nacional, y una mejora de $0,6 \%$ del producto para las provincias, repartido por igual entre la provincia de Buenos Aires $(0,3 \%)$, la gran ganadora del acuerdo, y el resto de las provincias (0,3\%) (Dalto 2017). La clave de bóveda para sostener 
ese acuerdo era la reforma previsional que, al modificar la fórmula de ajuste de las jubilaciones, liberaría recursos para que el tesoro afrontara las transferencias acordadas sin comprometer adicionalmente la meta fiscal. Fue esta última reforma la que determinaría el clima político en el cierre del año.

El gobierno propuso una ley para revisar la fórmula de actualización de los haberes jubilatorios. Los haberes pasaron de estar ajustados por la evolución de los salarios y la recaudación tributaria a estar en su gran mayoría (70\%) definidos por inflación. Además, la variación pasó de ser semestral a ser trimestral, pero con un atraso de seis meses en cuanto a los períodos de inflación de referencia. Estos cambios afectan a todas las jubilaciones y pensiones contributivas y no contributivas, a los beneficiarios de la Asignación Universal por hijo y a las asignaciones familiares. La reforma también extendía de manera optativa la edad jubilatoria, al dar la posibilidad a los trabajadores formales de continuar en sus puestos cinco años más allá de la edad de jubilación (65 para las mujeres y 70 para los hombres), período en el cual las empresas dejan de hacer aportes. Finalmente, en una concesión a los legisladores, la reforma garantizó el 82\% móvil a personas con 30 años de aportes y recibiendo la jubilación mínima (Ybarra 2017).

La primera crítica que generó la propuesta fue que el cambio de la fórmula disminuía el aumento que percibirían los jubilados. En particular, la decisión de empezar a aplicar la fórmula en marzo de 2018 tomando la inflación del tercer trimestre del 2017 implica un ajuste de entre el 4 y el 6\% (alrededor de \$5000 anuales en el 2018). Esto es porque los salarios (la base para la fórmula anterior) han comenzado a ganarle a la inflación en 2017 (Etchemendy 2017 y Gráfico 4). Una crítica adicional a la ley se basó en el período de transición, ya que se estaría dejando un semestre entero sin aumentos (Stang 2017).

Estos ajustes disminuyen el gasto estatal en alrededor de 60 mil millones de pesos anuales, reduciendo el déficit del sistema y compensando en parte la pérdida de recursos a manos de las provincias por el pacto fiscal (Obarrio 2017b). La situación deficitaria del sistema se había visto agravada tras la reparación histórica implementada por el gobierno antes de las elecciones y la disminución de las contribuciones de los empleadores para sueldos por debajo de $\$ 12.000$ brutos, contemplada en la reforma impositiva. Junto con la pérdida del $20 \%$ del Impuesto a las Ganancias, compensada apenas por la recaudación de un impuesto transitorio que requiere la prórroga periódica por parte del Congreso, las modificaciones introducidas contribuyen a desfinanciar al sistema de seguridad social (Etchemendy 2017).

Los mayores perdedores de la reforma son, entonces, los jubilados actuales y futuros. La reforma tocó una de las fibras más sensibles de la población argentina: el dinero de los jubilados. La oposición ganó las calles para rechazar el recorte. Las protestas incluyeron a la GCT, las dos CTA (Central de Trabajadores de la Argentina) y varias agrupaciones de izquierda y sindicatos. La CGT organizó el segundo paro general al gobierno de Macri. La oposición kirchnerista y de 
izquierda también participó de ellas. Esta fue la mayor crisis del gobierno desde que llegó a la Casa Rosada. La crisis se vio agravada por la respuesta oficial, recurriendo de manera indiscriminada al poder coercitivo del Estado para controlar a los manifestantes: cercó militarmente el Congreso con efectivos de Gendarmería, Prefectura y de la Policía Federal y reprimió la protesta con gases y balas de goma.

La ley se aprobó en este clima de violencia que duró casi una semana. El capítulo más polémico del paquete de reformas fue sancionado finalmente en Diputados con 126 votos a favor y 117 en contra. Decisivos para su aprobación fueron, además de los 107 votos del oficialismo, los 16 votos justicialistas aportados por provincias gobernadas por la oposición. ${ }^{9}$ La cooperación de las provincias requirió del gobierno $\$ 45.000$ millones extra en obras públicas y concesiones para las que aportaron esos votos, lo que terminó de destrabar la medida en ambas cámaras (Serra 2017; Ybarra 2017a). El pasaje de la ley le costó también al gobierno en términos de opinión pública: en el mes de diciembre, la aprobación del gobierno se derrumbó 10 puntos hasta un (todavía mayoritario) 55\% (Gráficos 3 y 4 ).

\section{Reforma laboral frustrada}

La propuesta de reforma laboral buscaba mejorar la rentabilidad empresarial para estimular la inversión: reducir el costo económico y administrativo del despido, abrir la puerta para que el trabajador "elija" no estar protegido por la Ley de Contrato de Trabajo (LCT) o los convenios colectivos, y facilitar la tercerización. En particular, hay un número de puntos del proyecto que generan resistencia entre los trabajadores organizados, a saber: la reducción de las indemnizaciones, la modificación de la LCT para igualar los derechos y obligaciones del empleador y del trabajador, y la exclusión del "trabajador autónomo económicamente dependiente" y de "trabajadores independientes y sus colaboradores" de la LCT al fomentar la tercerización (Etchemendy 2017).

Etchemendy (2017) explica que esta propuesta favorece claramente a los empresarios. En particular, la ley promueve el "blanqueo" de trabajadores informales dentro de la empresa sin que el empleador tenga que pagar una multa y disuadiendo a que el trabajador inicie acciones legales. Sin embargo, el empleador podría regularizar al empleado y después despedirlo, evitando un juicio por tener un trabajador no registrado, y el trabajador pierde la amenaza del juicio para que no lo despidan de su relación laboral no registrada. Para evitar este desenlace, el gobierno anterior prohibía la reducción de personal después de la regularización.

Ver La Nacion, Congresoscopio: “Uno por uno, cómo votó cada diputado la reforma previsional”, disponible en https://votaciones.lanacion.com.ar/diputados/leyes/2017\#ley=1474. 
En suma, los ganadores del proyecto de ley son las grandes empresas y los perdedores los trabajadores, sobre todo los más vulnerables por estar tercerizados, no registrados, o incluso regularizados pero con el riesgo de ser despedidos sin poder tomar represalias. En consecuencia, la mayor oposición a la reforma vino de la CGT. A diferencia de la previsional, que imponía costos a sectores con escasos recursos organizacionales, la reforma laboral afectaba a los sindicatos (Niedzwiecki 2014). La falta de disposición de estos últimos a asumir los costos de la reforma, no obstante los compromisos alcanzados con el gobierno, disuadió a los legisladores justicialistas a avanzar con la iniciativa (Ybarra 2017). En este caso, la negociación con los perdedores hizo inviable la propuesta en 2017, y la discusión fue aplazada para el año siguiente (Dapelo 2018).

\section{REFLEXIONES SOBRE EL ESTADO DE LA DEMOCRACIA ARGENTINA}

A juzgar por los acontecimientos de 2017, el balance del estado de la democracia en Argentina es positivo. Por un lado, si la alternancia en el gobierno es un requisito indispensable para una definición procedimental mínima de democracia, entonces la llegada al gobierno de Cambiemos es sin duda un indicador positivo de la vitalidad de la democracia argentina. Adicionalmente, el triunfo en las elecciones de medio término de la coalición gobernante aumenta las chances de que Mauricio Macri complete su mandato presidencial. Que un partido que no sea el justicialismo lleve a término su mandato es una novedad que Cambiemos parece en condiciones de realizar en 2019. Por otro lado, echando mano a las categorías de Roberts (2012), se podría argumentar también que el gobierno de Cambiemos contribuye a ordenar de manera programática la oferta electoral del sistema político argentino, y en esta medida ayuda a fortalecer la representación democrática. En efecto, con la llegada de Mauricio Macri al poder el fin de ciclo de la macroeconomía populista está siendo gestionado por una coalición que propone programáticamente una solución de mercado y ortodoxa (incluso si gradual) a los problemas heredados.

El balance es menos positivo si consideramos otros aspectos que hacen a la calidad institucional y la protección de los derechos humanos. El endurecimiento de la respuesta coercitiva a la movilización social, las posiciones revisionistas sobre el consenso democrático respecto al enjuiciamiento de los crímenes de la última dictadura, y el encarcelamiento de funcionarios del gobierno anterior sobre bases jurídicas discutibles son desarrollos que echan sombras sobre un régimen democrático que aparece no obstante plenamente consolidado.

Este informe mostró la estrategia de Cambiemos de cara a las elecciones y la estrategia de ajuste una vez ganadas. La desorganización y divisiones del polo justicialista luego de la derrota electoral contribuyeron decisivamente a ese resultado. Si la política se jugara exclusivamente en el terreno de la 
política partidaria, podríamos concluir que el gobierno de Mauricio Macri se encuentra en una situación inmejorable para intentar la reelección en 2019. No obstante, en los dos primeros años, el gobierno de Cambiemos puso a prueba también la sustentabilidad política de un programa de reestructuración económica y ajuste gradual. Lo que permitió al gobierno resolver en el tiempo el trade-off entre la búsqueda de sustentabilidad política y la persecución de la sustentabilidad económica, ocupándose primero de una y luego de otra, fue el acceso al financiamiento externo. Un endurecimiento de las condiciones de acceso a ese financiamiento, de naturaleza exógena o endógena al aumento del stock de deuda, colocará al gobierno en la situación de tener que resolver ese trade-off simultáneamente en tiempo presente. De qué manera el gobierno de Cambiemos encara ese desafío nos será revelado durante el año en curso.

\section{REFERENCIAS}

Arza, Camila. 2016. "All Children Equal? Between Expansion and Segmentation in Social Policies for Early Childhood in Argentina." Ponencia presentada en Research Committe 19 Poverty, Social Welfare and Social Policy Symposium, San José, Costa Rica, 25-27 de agosto.

Banco Central de la República Argentina. 2018a, abril. "Informe de Política Monetaria." Recuperado el 18 de junio de 2018 de http://www.bcra.gob.ar/Pdfs/PoliticaMonetaria/ IPOM0418.pdf.

Banco Central de la República Argentina. 2018b. "Principales Variables: LEBAC." Recuperado el 18 de junio de 2018 de http://www.bcra.gov.ar/PublicacionesEstadisticas/Principales_variables.asp.

Bertello, Fernando. 2017a, 24 de octubre. "En las zonas con influencia del agro, el Gobierno amplió los votos que tuvo en las PASO." Recuperado el 18 de junio de 2018 de https:/ / www.lanacion.com.ar/2075663-en-las-zonas-con-influencia-del-agro-el-gobierno-amplio-los-votos-que-tuvo-en-las-paso.

Bertello, Fernando. 2017b, 17 de octubre. "Productores del agro son optimistas por el clima de negocios y piden la reelección de Macri." Recuperado el 18 de junio de 2018 de https:/ / www.lanacion.com.ar/2072818-productores-del-agro-son-optimistas-por-elclima-de-negocios-y-piden-la-reeleccion-de-macri.

Burdman, Julio. 2017. “La misión." Le Monde diplomatique, edición Cono Sur 217.

Calvo, Ernesto. 2017, 27 de octubre. “CCómo sigue la cosa?” El Estadista. Recuperado el 18 de junio de 2018 de http:/ / elestadista.com.ar/?p=13455.

Centro de Estudios del Trabajo y el Desarrollo (CETyD). 2018, abril. "Boletín de Coyuntura Sociolaboral." Año 3, Volumen 7. Recuperado el 18 de junio de 2018 de http:/ /www. cetyd.unsam.edu.ar/boletin/CETyD-boletin-7-ampliado.pdf.

CIPPEC. 2017. “Cuadernos Electorales 2017." Recuperado el 18 de junio de 2018 de http:/ / oear.cippec.org/category/novedades/cuadernos-electorales/.

Dalto, Verónica. 2017, 29 de noviembre. “Con el pacto fiscal, la Nación cede \$ 74.600 millones a las provincias." Recuperado el 18 de junio de 2018 de https:/ /www.cronista.com/ economiapolitica/Con-el-pacto-fiscal-la-Nacion-cede--74.600-millones-a-las-provincias-20171129-0024.html.

Dapelo, Santiago. 2018, 19 de enero. "El Gobierno decidió desdoblar la reforma laboral." Recuperado el 18 de junio de 2018 de https:/ / www.lanacion.com.ar/2102218-sin-respaldo-el-gobierno-decidio-desarmar-la-reforma-laboral.

De Luca, Miguel y Andres Malamud. 2010. “Argentina: turbulencia económica, polarización social y realineamiento político." Revista de Ciencia Política 30 (2): 173-189. 
Etchemendy, Sebastián. 2017, 20 de diciembre. "Apuntes sobre la Economía Política de las Reformas PRO." artepolítica. Recuperado el 18 de junio de 2018 de: http:/ /artepolitica. $\mathrm{com} /$ articulos/apuntes-sobre-la-economia-politica-de-las-reformas-pro/.

Freille, Sebastián. 2015. “Do Private Campaing Contributions Affect Electoral Results? An Examination of Argentine National Elections." Ponencia presentada en el Seminario del Departamento de Ciencia Política y Estudios Internacionales, Universidad Torcuato Di Tella, Buenos Aires, 2 de julio.

Freytes, Carlos. 2015a, 25 de noviembre. "Clivajes territoriales, mandatos electorales y coaliciones de Gobierno." El Estadista. Recuperado el 18 de junio de 2018 de: http:// elestadista.com.ar $/$ ?p=9199.

Freytes, Carlos. 2015b. "The Cerrado Is Not the Pampas: Explaining Tax and Regulatory Policies on Agricultural Exports in Argentina and Brazil (2003-2013)." Ph.D. Dissertation, Northwestern University.

Freytes, Carlos y Sara Niedzwiecki. 2016. "A Turning Point in Argentine Politics. Demands for Change and Territorial Cleavages in the 2015 Presidential Election." Regional \& Federal Studies 26 (3): 381-394.

Gammacurta, Guillermo. 2017, 2 de noviembre. "Eliminan obligación de liquidar divisas de exportaciones." Recuperado el 18 de junio de 2018 de: http://www.ambito. com/902224-eliminan-obligacion-de-liquidar-divisas-de-exportaciones.

Indec. 2018a, marzo. "Estimador Mensual de Actividad Económica." Informes Técnicos 2 (62). Recuperado el 18 de junio de 2018 de: https:/ / www.indec.gob.ar/uploads/informesdeprensa/emae_05_18.pdf.

Indec. 2018b, marzo. "Mercado de trabajo. Indicadores socioeconómicos (EPH)." Informes Técnicos 2 (56). Recuperado el 18 de junio de 2018 de: https://www.indec.gob.ar/ uploads/informesdeprensa/indicadores_eph_4trim17.pdf.

Indec. 2018c, marzo. "Balanza de pagos, posición de inversión internacional y deuda externa." Informes Técnicos 2 (55). Recuperado el 18 de junio de 2018 de: https:/ / www.indec.gov. ar/uploads/informesdeprensa/bal_03_18.pdf.

Isonomía Consultores. 2018, marzp. "Isobarómetro. Encuesta nacional de opinión pública."s

La Nación. 2017a, 29 de septiembre. "La baja de las retenciones a la soja en 2018 le costará US\$ 1000 millones al Gobierno." Recuperado el 18 de junio de 2018 de: https: / /www. lanacion.com.ar/2067705-la-baja-de-las-retenciones-a-la-soja-en-2018-le-costara-us1000-millones-al-gobierno

La Nación. 2017b, 29 de octubre. "Una fuerte expansión oficialista en el Congreso, sin mayorías." Recuperado el 18 de junio de 2018 de: https://www.lanacion.com. ar/2077311-una-fuerte-expansion-oficialista-en-el-congreso-sin-mayorias.

Leiras, Marcelo. 2017. “¿Un nuevo escenario político? Jornada final.” Revista Anfibia. Recuperado el 18 de junio de 2018 de: http:/ / www.revistaanfibia.com/un-nuevo-escenario-politico-jornada-final/.

Ministerio de Hacienda. 2018. "Portal de Datos Económicos. Finanzas Públicas." Recuperado el 18 de junio de 2018 de: https:/ / www.minhacienda.gob.ar/datos/ .

Ministerio de Trabajo, Empleo y Seguridad Social. 2018, enero. "Situación y evolución del total de trabajadores registrados." Recuperado el 18 de junio de 2018 de: http: / / www. trabajo.gob.ar/estadisticas/trabajadoresregistrados/.

Mira, Cristina. 2016, 4 de octubre. "Postergan la baja de retenciones a la soja." Recuperado el 18 de junio de 2018 de: https://www.lanacion.com.ar/1943859-postergaron-la-bajade-retenciones-a-la-soja-sera-gradual-y-a-partir-de-2018

Murillo, M. Victoria, Julia M. Rubio y Jorge Mangonnet. 2016. “Argentina: el protagonismo de los votantes y la alternancia electoral." Revista de Ciencia Política 36 (1): 3-26.

Murillo, M. Victoria, Jorge Mangonnet y Julia M. Rubio. 2018. "Agricultural Boom and Electoral Behavior in the Argentine Countryside, 2007-2015." Latin American Politics and Society 60 (3): $1-27$.

Natanson, José. 2017. “La «ola amarilla» en Argentina. Reconfiguraciones tras el triunfo de Cambiemos." Nueva Sociedad 272: 4-12. 
Niedzwiecki, Sara. 2014. "The Effect of Unions and Organized Civil Society on Social Policy. Pension and Health Reforms in Argentina and Brazil (1988-2008)." Latin American Politics and Society 56 (4): 22-48.

Niedzwiecki, Sara. 2016. "Social Policies, Attribution of Responsibility, and Political Alignments. A Subnational Analysis of Argentina and Brazil." Comparative Political Studies 49 (4): 457-498.

Niedzwiecki, Sara y Jennifer Pribble. 2017. “Social Policies and Center-Right Governments in Argentina and Chile." Latin American Politics and Society 59 (3): 72-97.

Niedzwiecki, Sara. 2018. Uneven Social Policies. The Politics of Subnational Variation in Latin America. Cambridge: Cambridge University Press.

Obarrio, Mariano. 2017a, 11 de noviembre. "Compensarán a Vidal por el Fondo del Conurbano y revisarán impuestos." Recuperado el 18 de junio de 2018 de: https:/ /www. lanacion.com.ar/2081040-compensaran-a-vidal-por-el-fondo-del-conurbano-y-revisaran-impuestos.

Obarrio, Mariano. 2017b, 17 de noviembre. "Macri compensó a las provincias y destrabó dos reformas cruciales." Recuperado el 18 de junio de 2018 de: https://www.lanacion. com.ar/2083160-macri-compenso-a-las-provincias-y-destrabo-dos-reformas-cruciales.

Obarrio, Mariano. 2017c, 19 de diciembre. "Reforma previsional: Diputados aprobó la ley tras 12 horas de debate y una jornada cargada de violencia." Recuperado el 18 de junio de 2018 de: https://www.lanacion.com.ar/2092710-reforma-previsional-diputados-sanciono-la-ley-tras-una-jornada-de-violencia.

Pagni, Carlos. 2017, 7 de noviembre "Ya llama más la atención la impunidad que la corrupción." Recuperado el 18 de junio de: https://www.lanacion.com.ar/2079984-ya-llama-mas-la-atencion-la-impunidad-que-la-corrupcion.

Presidencia de la Nación Argentina. 2017. “Carta de Jefatura de Gabinete. Tres Pilares para el Desarrollo Humano." Recuperado el 18 de junio de 2018 de: https:/ / www.casarosada. gob.ar/cartajefatura.

Roberts, Kenneth. 2012. "Market Reform, Programmatic (De)alignment, and Party System Stability in Latin America." Comparative Political Studies 46 (11): 1422-1452.

Semán, Pablo. 2017. “¿Un nuevo escenario político? Jornada 2." Revista Anfibia. Recuperado el 18 de junio de 2018 de: http://www.revistaanfibia.com/un-nuevo-escenario-politico-jornada-2/.

Serra, Laura. 2017, 1 de diciembre. “Más de \$ 45.000 millones debió ceder el Gobierno para aprobar las reformas." Recuperado el 18 de junio de 2018 de: https:/ /www.lanacion. com.ar/2096873-mas-de-45000-millones-debio-ceder-el-gobierno-para-aprobar-lasreformas.

Serra, Laura. 2018a, 7 de enero. "El Gobierno logró que se apruebe el 72,4\% de sus proyectos de ley." Recuperado el 18 de junio de 2018 de: https: / / www.lanacion.com.ar/2098485el-gobierno-logro-que-se-apruebe-el-724-de-sus-proyectos-de-ley.

Serra, Laura. 2018b, 11 de febrero. "Por la emergencia, suman a 100.000 beneficiarios de planes." Recuperado el 18 de junio de 2018 de: https:/ / www.lanacion.com.ar/2108360por-la-emergencia-suman-a-100000-beneficiarios-de-planes.

Stang, Silvia. 2017, 29 de noviembre. "La reforma jubilatoria llega al Congreso: analistas proponen un mecanismo de transición para el cambio de fórmula." Recuperado el 18 de junio de 2018 de: https://www.lanacion.com.ar/2086725-la-reforma-jubilatoria-llega-al-congreso-analistas-proponen-un-mecanismo-de-transicion-para-el-cambio-de-formula.

Veneranda, Marcelo. 2017, 14 de diciembre: "Quiénes son los gobernadores que le aportarían al Gobierno los votos y el quórum para la reforma previsional." Recuperado el 18 de junio de 2018 de: http:/ / www.lanacion.com.ar/2091405-gobernadores-prevional.

Vommaro, Gabriel y Mariana Gené. 2017. "Argentina: el año de Cambiemos." Revista de Ciencia Política 37 (2): 231-253.

Vommaro, Gabriel. 2017a. La larga marcha de Cambiemos. Buenos Aires: Siglo XXI Editores. 
Vommaro, Gabriel. 2017b. "La centroderecha y el «cambio cultural» argentino." Revista Nueva Sociedad 270: 4-13.

Ybarra, Gustavo. 2017a, 24 de noviembre. "El peronismo postergó la reforma laboral y descolocó al Gobierno." Recuperado el 18 de junio de 2018 de: https: / www.lanacion.com. ar/2085267-el-peronismo-postergo-la-reforma-laboral-y-descoloco-al-gobierno.

Ybarra, Gustavo. 2017b, 20 de noviembre. "Aval del Congreso a las reformas acordadas con los gobernadores." Recuperado el 18 de junio de 2018 de: http:/ /www.lanacion.com. ar/2087012-aval-del-congreso-a-las-reformas-acordadas-con-los-gobernadores.

Zarazaga, Rodrigo. 2017, 23 de agosto. "El peronismo tiene su propia grieta." Recuperado el 18 de junio de 2018 de: https://www.lanacion.com.ar/2055623-el-peronismo-tiene-su-propia-grieta.

Carlos Freytes es profesor investigador ordinario en el Departamento de Ciencia Política y Relaciones Internacionales de la Universidad Torcuato Di Tella. Obtuvo su doctorado (Ph.D.) en Ciencia Política por la Universidad Northwestern (IL) y un Máster en Ciencia Política y Sociología por FLACSO-Buenos Aires. Su área de especialización es la economía política comparada. Su trabajo se focaliza en la intersección entre política electoral y política de representación de intereses y en los conflictos distributivos en torno a la regulación de actividades extractivas y la agricultura de exportación. En su tesis doctoral estudió cómo el federalismo afecta la representación política del sector agroexportador en Argentina y Brasil. Ha publicado sobre sus temas de investigación en Desarrollo Económico, Revista de la SAAP y Regional and Federal Studies. Ha sido profesor visitante de posgrado en la Universidad Católica de Córdoba, la Universidad de Bologna, sede Buenos Aires, y es actualmente profesor de Política Latinoamericana en el Instituto del Servicio Exterior de la Nación (ISEN). Email: cfreytes@utdt.edu

Sara Niedzwiecki es profesora asistente del Departamento de Política de la University of California, Santa Cruz. Es doctora en Ciencia Política por la University of North Carolina at Chapel Hill y Licenciada por la Universidad Torcuato di Tella. Estudia políticas sociales y política subnacional en América Latina. Su libro Uneven Social Policies: the Politics of Subnational Variation in Latin America fue publicado en Cambridge University Press en 2018. Es coautora del libro Measuring Regional Authority: A Postfunctionalist Theory of Governance (Oxford University Press, 2016). Su trabajo también ha sido publicado por Comparative Political Studies, Electoral Studies, Latin American Politics and Society, Studies in Comparative International Development, Journal of Politics in Latin America, Regional and Federal Studies, PS: Political Science and Politics, International Political Science Review y Saúde Coletiva. 